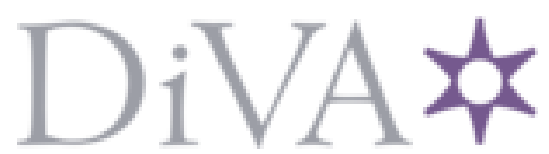

http://www.diva-portal.org

This is the published version of a paper published in Tissue Engineering. Part A.

Citation for the original published paper (version of record):

de Peppo, G., Svensson, S., Lennerås, M., Synnergren, J., Stenberg, J. et al. (2010)

Human Embryonic Mesodermal Progenitors Highly Resemble Human Mesenchymal Stem Cells and Display High Potential for Tissue Engineering Applications.

Tissue Engineering. Part A, 16(7): 2161-2182

http://dx.doi.org/10.1089/ten.TEA.2009.0629

Access to the published version may require subscription.

N.B. When citing this work, cite the original published paper.

This is a copy of an article published in Tissue engineering: Part A. @ 2010 Mary Ann Liebert, Inc.; Tissue engineering: Part A is available online at: http://online.liebertpub.com.

Permanent link to this version:

http://urn.kb.se/resolve?urn=urn:nbn:se:his:diva-4310 


\title{
Human Embryonic Mesodermal Progenitors Highly Resemble Human Mesenchymal Stem Cells and Display High Potential for Tissue Engineering Applications
}

\author{
Giuseppe Maria de Peppo, M.Sc., ${ }^{1,2}$ Sara Svensson, M.Sc., ${ }^{1,2}$ Maria Lennerås, M.Sc., ${ }^{2,3}$ \\ Jane Synnergren, Ph.D., ${ }^{4,5}$ Johan Stenberg, M.Sc., ${ }^{5}$ Raimund Strehl, Ph.D.,, Johan Hyllner, Ph.D., 2,6 \\ Peter Thomsen, Ph.D., ${ }^{1,2}$ and Camilla Karlsson, Ph.D.,
}

Adult stem cells, such as human mesenchymal stem cells (hMSCs), show limited proliferative capacity and, after long-term culture, lose their differentiation capacity and are therefore not an optimal cell source for tissue engineering. Human embryonic stem cells (hESCs) constitute an important new resource in this field, but one major drawback is the risk of tumor formation in the recipients. One alternative is to use progenitor cells derived from hESCs that are more lineage restricted but do not form teratomas. We have recently derived a cell line from hESCs denoted hESC-derived mesodermal progenitors (hES-MPs), and here, using genome-wide microarray analysis, we report that the process of hES-MPs derivation results in a significantly altered expression of hESC characteristic genes to an expression level highly similar to that of hMSCs. However, hES-MPs displayed a significantly higher proliferative capacity and longer telomeres. The hES-MPs also displayed lower expression of HLA class II proteins before and after interferon- $\gamma$ treatment, indicating that these cells may somewhat be immunoprivileged and potentially used for HLA-incompatible transplantation. The hES-MPs are thus an appealing alternative to hMSCs in tissue engineering applications and stem-cell-based therapies for mesodermal tissues.

\section{Introduction}

$\mathbf{T}$ ISSUE ENGINEERING IS AN emerging field of research aimed at regenerating functional tissues by combining cells with a supporting substrate. Stem cells are suitable cell types for this application owing to their expansion potential and ability to differentiate into a variety of tissues. Several different embryonic stem cell lines and adult stem cell sources have been used for this purpose ${ }^{1-4}$ underlining that some specific cell types may give better results in some particular applications. Among them, human embryonic stem cells (hESCs) constitute an important new resource in tissue engineering, mainly because of an extensive differentiation capacity and high proliferative potential. In fact, many adult organ-specific cells and stem cells show a limited proliferative capacity and, after long-term in vitro culture, lose their functional quality. ${ }^{5}$ On the other hand, a major disadvantage with hESCs is the risk of tumor formation in the recipients. ${ }^{6}$ hESC-derived mesodermal progenitors (hES-
MPs) are derived from hESCs but are more lineage restricted and do not form teratomas in vivo. Similarly to hESCs, hESMPs have a capacity for self-renewal and differentiation, but these properties are more limited. ${ }^{7}$

The derivation of hES-MPs from hESCs using different protocols has been described earlier. ${ }^{8-12}$ None of these protocols address the important aspects of xeno-free derivation, robustness, and safety for the use in tissue engineering and cell therapies. We therefore recently developed an optimized protocol resulting in simple and reproducible derivation of hES-MPs from undifferentiated hESCs. ${ }^{7}$ Multiple hES-MP cell lines have been derived and characterized using this protocol, including a xeno-free hES-MP cell line from xenofree parental hESCs, and their differentiation capacity toward tissues of the mesodermal lineage, including the osteogenic, chondrogenic, and adipogenic lineages has been demonstrated. $^{7}$ The mesodermal commitment of the hESMPs suggests that these cells are closely related to stem cells of the mesenchymal lineage and raises the urge for further

\footnotetext{
${ }^{1}$ Department of Biomaterials, Sahlgrenska Academy at University of Gothenburg, Göteborg, Sweden.

${ }^{2}$ BIOMATCELL VINN Excellence Center of Biomaterials and Cell Therapy, Göteborg, Sweden.

${ }^{3}$ TATAA Biocenter AB, Göteborg, Sweden.

${ }^{4}$ School of Life Sciences, University of Skövde, Skövde, Sweden.

${ }^{5}$ Department of Clinical Chemistry and Transfusion Medicine, Institute of Biomedicine, Sahlgrenska University Hospital, University of Gothenburg, Göteborg, Sweden.

${ }^{6}$ Cellartis AB, Göteborg, Sweden.
} 
characterization. Human mesenchymal stem cells (hMSCs) represent a source of pluripotent cells that are already in various phases of clinical application. However, the use of hMSCs in tissue engineering has been hampered largely due to their low proliferation, finite life span, and gradual loss of their stem cell properties during ex vivo expansion. ${ }^{5}$

Today, the transcriptional changes occurring during hESMP derivation have not been studied and it is not either known how closely the hES-MPs resemble hMSCs. There is further a lack of knowledge concerning the immunological properties of these hES-MPs as well as their regulation of senescence and proliferative capacity. These questions are a prerequisite to investigate in order to replace hMSCs with hESC-derived progenitor cells in future tissue engineering applications, which prompted us to comprehensively study these issues.

\section{Materials and Methods}

\section{Cell types and culture conditions}

The undifferentiated hESC lines used in this study were the SA167, SA002.5, and SA461, derived and characterized at Cellartis AB, Gothenburg, Sweden. Detailed protocols are available at Cellartis (www.cellartis.com). The hES-MP cell lines were derived from the three undifferentiated hESC lines described above, as previously reported. ${ }^{7}$ hMSCs were isolated from bone marrow aspirates from the iliac crest of patients undergoing spinal fusion (age range 13-20 years) and expanded as described previously. ${ }^{13}$ The cells were harvested for RNA isolation in passage 3 when the cells reached $80 \%$ confluence. The donation of bone marrow was approved by the ethics committee at the Medical Faculty at Gothenburg University (Dnr. 532-04).

\section{Flow cytometry analysis}

Flow cytometry analysis was used to confirm isolation and enrichment of hMSCs, verify microarray results, and examine expression of immunological markers. To verify enrichment of hMSCs, cells were stained with CD34-PerCP, CD45-FITC, CD105-FITC, and CD166-PE (all from Ancell). To verify the microarray results, hMSCs, hES-MPs, and hESCs were stained with CD44-FITC (BD Biosciences), CD58-PE (BD Biosciences), CD47-FITC (BD Biosciences), and CD166-PE. Expression of immunological markers was studied in both hMSCs and hES-MPs at low and high passage (defined as 5 and 50 population doublings [PDs], respectively) as well as before and after a 5-day treatment with interferon- $\gamma$ (IFN- $\gamma$ ) (100 U/mL; R\&D Systems Europe). The cells were then stained with HLA-ABC-FITC, HLA-DR-FITC, CD80-FITC (all from BD Biosciences), and CD86-PerCP-Cy5 (Ancell). All samples were analyzed using the FACS Aria flow cytometer (Becton Dickinson) using FACS Diva software (Becton Dickinson).

\section{$R N A$ isolation}

Total RNA was extracted using the RNeasy ${ }^{\circledR}$ Minikit (Qiagen $\mathrm{GmbH}$ ) according to manufacturer's instructions. DNAse treatment was performed to eliminate any contamination from genomic DNA according to Qiagen RNase Free DNase Set (Qiagen $\mathrm{GmbH}$ ) protocol.

\section{Microarray analysis}

RNA from hESCs, hES-MPs, and hMSCs was subjected to gene expression analysis using the oligonucleotide microarray HG-U133plus2.0 (Affymetrix) according to manufacturer's recommendations. Raw expression data were normalized and subsequently analyzed with GeneChip Operating Software 1.4 (GCOS; Affymetrix). Comparative and statistical analyses were performed with the BIORETIS Web tool (www.bioretisanalysis.de). Genes were selected for further analysis only if (1) the absolute call for the gene was present for at least one of the three cell types, (2) three out of three comparisons had to be considered increased or decreased according to Affymetrix algorithm, and (3) the average fold change (FC) should be at least twofold. Using these qualitative and quantitative filtering criteria, we performed two comparative analyses, one between hES-MPs and hESCs and the other between hES-MPs and hMSCs. Functional classification into five different categories-transcription factors, extracellular matrix components, growth factors, membrane receptors, and cell adhesion molecules-was performed using annotations from the Gene Ontology Annotation Database. ${ }^{14}$ Further, expression of 48 genes known to be overexpressed in hESCs compared with differentiated cell types, 40 genes specifically expressed in hESCs, and 30 selected genes underexpressed in hESCs compared with differentiated cell types was investigated. ${ }^{15}$ For these genes, the mean expression level from different probe sets of each gene was calculated and reported in Table 1A-C. The significance level was determined applying the Welch's $t$ test on log2-transformed signal values. Hierarchical cluster analysis was performed using log2-transformed signals of all the replicates using Genesis 1.7.3 software. ${ }^{16}$

To explore the similarity in global gene expression pattern across investigated samples, the correlation was calculated using standard function in $\mathrm{R}$ statistical software. Spearman was used as correlation coefficient, and genes with missing values were excluded from the calculation. The interpretation of this analysis is as follows: 1 means perfect correlation, -1 means negative correlation, and 0 means no correlation.

The percentage of genes with an FC $\leq 3$ between pairs of samples was calculated for all three comparisons (hES-MPs vs. hMSCs, hES-MPs vs. hESCs, and hMSCs vs. hESCs). This FC-threshold was defined based on the results from comparisons of the biological replicates. To define the background variation, the FCs between pair-wise replicates were calculated, and the results showed that $90 \%$ of all the genes have an FC $\leq 3$ between any two replicates of a sample.

To observe the similarity in global gene expression across the investigated cell samples, scatter plots were generated between average signals of pairs of samples using standard function in $\mathrm{R}$.

\section{Analysis of protein interaction networks}

To investigate possible interactions among proteins from differentially expressed genes (defined by having an FC of at least 10) between hES-MPs and hESCs or hES-MPs and hMSCs and to identify hub proteins, the search tool STRING (http://string.embl.de) was used to mine for recurring instances of neighboring genes. A gene of interest was classified as a hub if it had at least five interactions with other genes. $^{14}$ 
Table 1A. Microarray Results of 40 Genes Specifically Expressed in Human Embryonic Stem Cells

\begin{tabular}{|c|c|c|c|c|c|}
\hline Gene name & $\begin{array}{c}\text { Gene } \\
\text { abbreviation }\end{array}$ & $\begin{array}{c}F C h E S-M P \text { vs. } \\
h E S C s\end{array}$ & $\mathrm{p}$ & $\begin{array}{c}F C h E S-M P \text { vs. } \\
h M S C s\end{array}$ & $\mathrm{p}$ \\
\hline Abhydrolase domain containing 9 & ABHD9 & $-\mathbf{1 7 . 4}$ & 0.0000 & 1.5 & 0.3031 \\
\hline Barren homolog protein 1 & $B R R N 1$ & -4.2 & 0.0087 & 22.6 & 0.0000 \\
\hline Chromosome 14 open reading frame 115 & C14orf115 & -14.3 & 0.0000 & 1.7 & 0.1378 \\
\hline Cell division cycle 25 homolog A & CDC25A & -10.7 & 0.0000 & 6.1 & 0.2463 \\
\hline CHK2 checkpoint homolog & CHEK2 & -4.2 & 0.0000 & -1.1 & 0.6316 \\
\hline Claudin 6 & CLDN6 & -213.7 & 0.0000 & 0.6 & 0.2859 \\
\hline Chromosome $X$ open reading frame 15 & CXorf15 & -3.2 & 0.0000 & 1.1 & 0.5589 \\
\hline Cytochrome P450, family 26 , subfamily A1 & CYP26A1 & -81.9 & 0.0000 & 2.1 & 0.2116 \\
\hline Defective in sister chromatid cohesion protein 1 & DCC1 & -3.8 & 0.0081 & 1.3 & 0.3638 \\
\hline DNA (cytosine-5-)-methyltransferase 3 alpha & DNMT3A & -4.3 & 0.0021 & 0.7 & 0.2329 \\
\hline Deoxythymidylate kinase & DTYMK & 1.1 & 0.4926 & 1.4 & 0.4324 \\
\hline $\mathrm{EPH}$ receptor $\mathrm{A} 1$ & EPHA1 & -21.3 & 0.0002 & 0.0 & 0.4250 \\
\hline Ets variant gene 4 & ETV4 & -3.5 & 0.0001 & 2.1 & 0.0209 \\
\hline LINE-1 type transposase domain containing 1 & FLJ10884 & -226.3 & 0.0000 & 0.3 & 0.4757 \\
\hline FLJ20105 protein & FLJ20105 & -1.7 & 0.0047 & 17.7 & 0.0000 \\
\hline Apoptosis enhancing nuclease & FLJ12484 & -1.7 & 0.0070 & 1.3 & 0.1510 \\
\hline Growth differentiation factor 3 & GDF3 & -9.3 & 0.0000 & 1.1 & 0.5610 \\
\hline Gap junction protein, gamma 1 & GJA7 & 0.6 & 0.4198 & 6.9 & 0.0033 \\
\hline G protein-coupled receptor 19 & GPR19 & -24.6 & 0.0000 & 2.3 & 0.0391 \\
\hline G protein-coupled receptor 23 & GPR23 & -4.3 & 0.0012 & 2.1 & 0.0069 \\
\hline Helicase & HELLS & -2.5 & 0.0933 & 19.5 & 0.0011 \\
\hline HESX homeobox 1 & HESX1 & -84.4 & 0.0000 & -4.8 & 0.0007 \\
\hline KIAA0523 protein & KIAA0523 & -2.7 & 0.0356 & -3.4 & 0.0614 \\
\hline Lin-28 homolog & LIN28 & -496.5 & 0.0000 & 2.7 & 0.0001 \\
\hline Minichromosome maintenance complex 10 & MCM10 & -4.3 & 0.0000 & 9.7 & 0.0097 \\
\hline Dysbindin & MGC3101 & -2.3 & 0.0782 & 2.6 & 0.2980 \\
\hline V-myb myeloblastosis viral oncogene-like 2 & MYBL2 & -8.5 & 0.0000 & 3.0 & 0.0000 \\
\hline Nanog homeobox & NANOG & -1482.0 & 0.0000 & -4.3 & 0.0001 \\
\hline Origin recognition complex, subunit 1-like & ORC1L & -16.1 & 0.0000 & 4.6 & 0.5496 \\
\hline Origin recognition complex, subunit 2-like & ORC2L & -2.6 & 0.0000 & 1.1 & 1.0000 \\
\hline POU class 5 homeobox 1 & POU5F1 & -445.7 & 0.0000 & 1.0 & 0.0558 \\
\hline PR domain containing 14 & PRDM14 & -10.1 & 0.0000 & 2.2 & 0.0007 \\
\hline Chromosome 2 open reading frame 56 & PRO1853 & -2.2 & 0.0045 & 0.5 & 0.2072 \\
\hline PWP2 periodic tryptophan protein homolog & $\mathrm{PWP} 2 \mathrm{H}$ & -0.8 & 0.0915 & 1.2 & 0.4675 \\
\hline RNA binding motif protein 14 & RBM14 & -7.7 & 0.0000 & 2.4 & 0.0000 \\
\hline RNA, U3 small nucleolar interacting protein 2 & RNU3IP2 & -1.8 & 0.0127 & 1.5 & 0.0032 \\
\hline Solute carrier family 5 member 6 & SLC5A6 & -5.4 & 0.0000 & 1.7 & 0.0012 \\
\hline SLD5 homolog & SLD5 & -2.5 & 0.0337 & 4.0 & 0.2560 \\
\hline Teratocarcinoma-derived growth factor 1 & TDGF1 & -315.2 & 0.0000 & 1.5 & 0.0145 \\
\hline Zic family member 3 & ZIC3 & -51.6 & 0.0000 & -1.1 & 0.9404 \\
\hline
\end{tabular}

Genes significantly regulated are in boldface.

FC, fold change; hESC, human embryonic stem cell; hES-MP, hESC-derived mesodermal progenitor; hMSC, human mesenchymal stem cell.

\section{Quantitative real time-polymerase chain reaction}

Microarray results were verified using real-time polymerase chain reaction (PCR), flow cytometry, and immunohistochemistry. For real-time PCR, reverse transcription was carried out using iScript cDNA Synthesis Kit (Bio-Rad) according to manufacturer's instructions. Design of primers for TDGF, TGF- $\beta 2 R$, RUNX2,COL1A1, LHX8, and BMP2R was performed using the Primer3 Web-based software. Primer sequences and detailed protocols are available at TATAA Biocenter AB, Göteborg, Sweden (www.tataa.com). Statistical analysis for real-time PCR data was performed using the Mann-Whitney test. Differences were accepted to be statistically significant at $p \leq 0.05\left(^{*}\right)$.

\section{Immunohistochemistry}

Monoclonal antibodies against the pluripotency markers OCT4 and NANOG were used to immunohistochemically verify the microarray results. The procedure used for the analysis has previously been described. ${ }^{17}$

\section{Proliferative capacity}

To compare the expansion ability of hMSCs and hES-MPs, cells were expanded as described above and passaged when one of them reached $80 \%$ confluence. At each passage, cells were counted in a hemocytometer and the number of cell doublings was calculated.

\section{Telomerase activity}

Telomerase activity was evaluated using the TeloTAGGG Telomerase PCR ELISA ${ }^{\text {PLUS }}$ kit (Roche Diagnostics Scandinavia $\mathrm{AB}$ ). Both hMSCs and hES-MPs at low and high passage were analyzed according to manufacturer's recommendations. The PCR was performed using a Thermal Cycler 2720 
Table 1B. Microarray Results of 48 Genes Known to Be Overexpressed in Human Embryonic Stem Cells Compared with Differentiated Cell Types

\begin{tabular}{|c|c|c|c|c|c|}
\hline Gene name & $\begin{array}{c}\text { Gene } \\
\text { abbreviation }\end{array}$ & $\begin{array}{c}F C \text { hES-MP vs. } \\
h E S C s\end{array}$ & $\mathrm{p}$ & $\begin{array}{l}h E S-M P \\
h M S C S\end{array}$ & $\mathrm{p}$ \\
\hline Aminoadipate-semialdehyde synthase & AASS & -5.3 & 0.0000 & -1.7 & 0.3257 \\
\hline Alkaline phosphatase, liver/bone/kidney & $A L P L$ & -27.3 & 0.0000 & -4.0 & 0.0546 \\
\hline $\begin{array}{l}\text { Bone morphogenetic protein receptor, } \\
\text { type } 1 \mathrm{~A}\end{array}$ & $B M P R 1 A$ & -3.0 & 0.0000 & 1.3 & 0.0003 \\
\hline $\begin{array}{l}\text { BUB1 budding uninhibited by } \\
\text { benzimidazoles } 1\end{array}$ & BUB1 & -6.0 & 0.0212 & 4.0 & 0.2569 \\
\hline CCAAT/enhancer binding protein zeta & CEBPZ & -3.7 & 0.0000 & 1.1 & 0.1389 \\
\hline Collapsin response mediator protein 1 & CRMP1 & -4.1 & 0.0000 & 2.7 & 0.0000 \\
\hline Cytochrome P450, family 26, subfamily A 1 & CYP26A1 & -81.9 & 0.0000 & 2.1 & 0.2116 \\
\hline DNA (cytosine-5-)-methyltransferase 3 beta & DNMT3B & -79.4 & 0.0000 & 1.5 & 0.0003 \\
\hline Developmental pluripotency associated 4 & DPPA4 & -21.0 & 0.0000 & 7.9 & 0.1538 \\
\hline GABA A receptor, beta 3 & GABRB3 & -34.4 & 0.0004 & -0.2 & 0.3643 \\
\hline Galanin prepropeptide & $G A L$ & -16.3 & 0.0143 & 2.6 & 0.0543 \\
\hline Growth differentiation factor 3 & GDF3 & -9.3 & 0.0000 & 1.1 & 0.5610 \\
\hline Glypican 4 & GPC4 & -58.2 & 0.0000 & -6.1 & 0.0017 \\
\hline Helicase & HELLS & -2.5 & 0.0933 & 19.5 & 0.0011 \\
\hline HRAS-like suppressor 3 & HRASLS3 & 1.4 & 0.1165 & -1.6 & 0.0071 \\
\hline Heat shock $70 \mathrm{kDa}$ protein 4 & HSPA4 & -3.5 & 0.0000 & 1.6 & 0.0285 \\
\hline Indoleamine-pyrrole 2,3 dioxygenase & IDO1 & -5.5 & 0.0021 & 1.1 & 0.5527 \\
\hline Integrin beta 1 binding protein 3 & ITGB1BP3 & -38.2 & 0.0000 & -1.3 & 0.3081 \\
\hline KIAA0523 protein & KIAA0523 & -2.7 & 0.0356 & -3.4 & 0.0614 \\
\hline Leukocyte cell derived chemotaxin 1 & LECT1 & -20.2 & 0.0000 & 1.7 & 0.1637 \\
\hline Left-right determination factor 1 & LEFTY1 & -14.3 & 0.0014 & -1.1 & 0.3309 \\
\hline Lin-28 homolog (C. elegans) & LIN28 & -496.5 & 0.0000 & 2.7 & 0.0977 \\
\hline Mannose-6-phosphate receptor & $M 6 P R$ & 0.6 & 0.0056 & 1.8 & 0.0003 \\
\hline Minichromosome maintenance complex 5 & MCM5 & -9.5 & 0.0000 & 9.2 & 0.0002 \\
\hline Microsomal glutathione S-transferase 1 & MGST 1 & -1.3 & 0.1750 & -1.2 & 0.2586 \\
\hline MutS homolog 2 & MSH2 & -8.0 & 0.0000 & -1.0 & 1.0000 \\
\hline Methylenetetrahydrofolate dehydrogenase & MTHFD1 & 1.3 & 0.0270 & 0.1 & 0.5060 \\
\hline Nanog homeobox & NANOG & -1482.0 & 0.0000 & -4.3 & 0.0000 \\
\hline Nuclear autoantigenic sperm protein & NASP & -4.7 & 0.0745 & 1.6 & 0.0307 \\
\hline Origin recognition complex, subunit 1-like & ORCIL & -16.1 & 0.0000 & 4.6 & 0.0001 \\
\hline PHD finger protein 17 & PHF17 & -4.0 & 0.0000 & -2.0 & 0.0002 \\
\hline Pim-2 oncogene & PIM2 & -4.5 & 0.0000 & -1.0 & 0.9369 \\
\hline Phosplipase A2, group XVI & PLA2G16 & -35.1 & 0.0000 & $-\mathbf{1 7 . 1}$ & 0.0000 \\
\hline POU class 5 homeobox 1 & POU5F1 & -445.7 & 0.0000 & 1.0 & 1.0000 \\
\hline $\begin{array}{l}\text { Phosphoribosyl pyrophosphate } \\
\text { amidotransferase }\end{array}$ & PPAT & -1.7 & 0.0368 & 0.5 & 0.5055 \\
\hline PC4 and SFRS1 interacting protein 1 & PSIP1 & -3.7 & 0.0384 & -0.7 & 0.4442 \\
\hline Sema domain $6 \mathrm{~A}$ & SEMA6A & -37.3 & 0.1394 & 1.9 & 0.3944 \\
\hline Selenophosphate synthetase 1 & SEPHS1 & -7.5 & 0.0000 & 2.0 & 0.0130 \\
\hline Solute carrier family 16 , member 1 & SLC16A1 & -3.8 & 0.0000 & 1.7 & 0.0024 \\
\hline $\begin{array}{l}\text { Small nuclear ribonucleoprotein } \\
\text { polypeptide } \mathrm{N}\end{array}$ & SNRPN & -2.1 & 0.2068 & 1.5 & 0.4131 \\
\hline SNRPN upstream reading frame & SNRPN & -4.2 & 0.0000 & 2.2 & 0.0037 \\
\hline SRY (sex determining region Y)-box 2 & SOX2 & -22.5 & 0.0001 & 3.6 & 0.3468 \\
\hline Teratocarcinoma-derived growth factor 1 & TDGF1 & -315.2 & 0.0000 & 1.5 & 0.4168 \\
\hline Telomeric repeat binding factor 1 & TERF1 & -10.7 & 0.0000 & 0.1 & 0.4638 \\
\hline UDP-glucose pyrophosphorylase 2 & UGP2 & -2.6 & 0.0010 & -0.1 & 0.4705 \\
\hline Uracil-DNA glycosylase & UNG & -3.4 & 0.0000 & 1.4 & 0.0213 \\
\hline Ubiquitin specific peptidase $9, \mathrm{X}$-linked & USP9X & -2.0 & 0.1573 & -0.3 & 0.0534 \\
\hline Zic family member 3 & ZIC3 & -51.6 & 0.0000 & -1.1 & 0.9250 \\
\hline
\end{tabular}

Genes significantly regulated are in boldface.

(Applied Biosystems), and the absorbance was read at $450 \mathrm{~nm}$ using the iEMS reader MF (Labsystems) microtiter plate reader and Ascent software. All samples were analyzed in triplicates, and heat-treated samples were used as negative control.

\section{Telomere length}

To investigate the length of the telomeres, DNA was isolated with Qiagen DNeasy Blood \& Tissue Kit (Qiagen AB) according to the manufacturer's protocol from both hMSCs 
Table 1C. Microarray Results of 30 Selected Genes Underexpressed in Human Embryonic Stem Cells Compared with Differentiated Cell Types

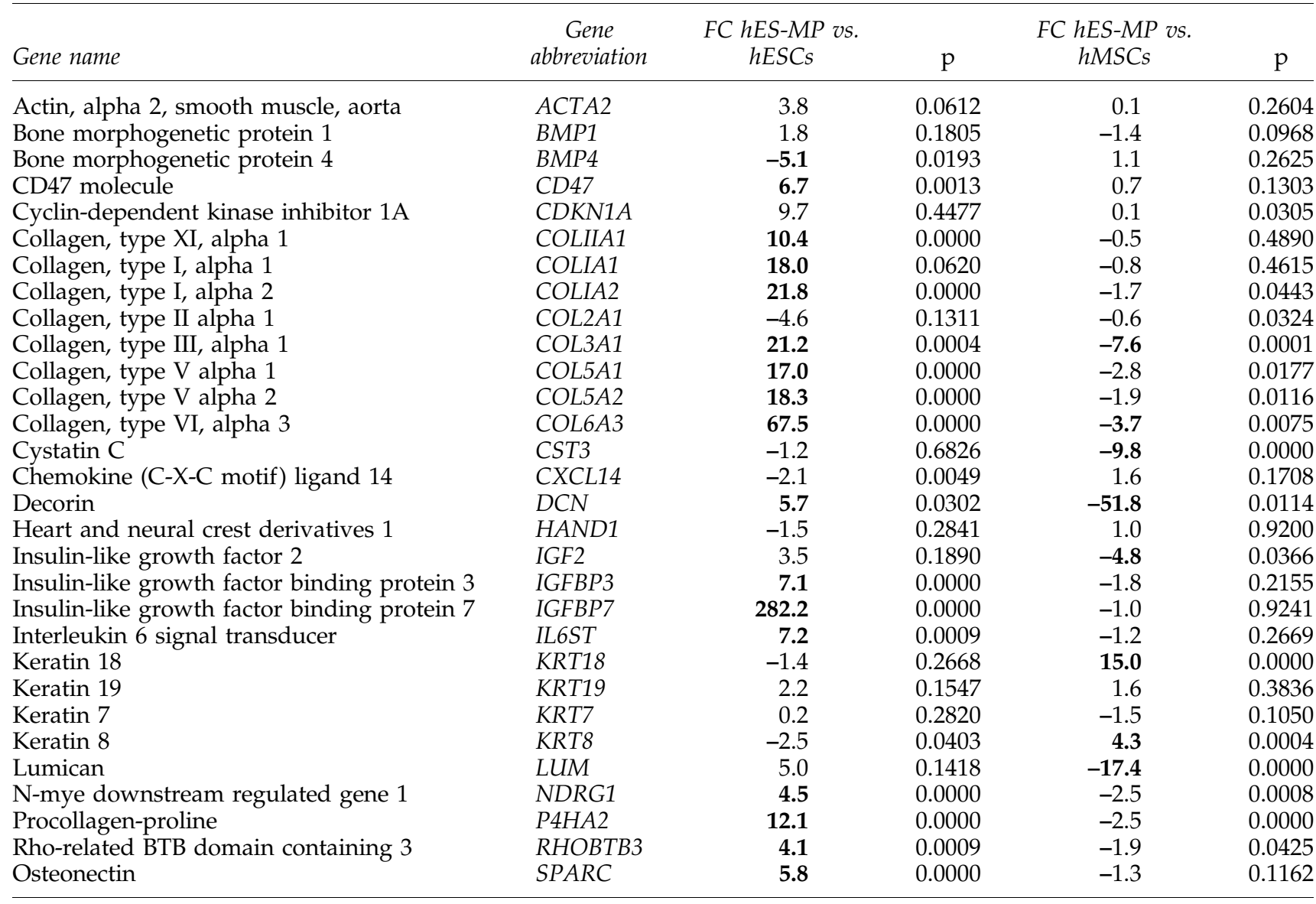

Genes significantly regulated are in boldface.

and hES-MPs at low and high passage. After isolation of DNA, the length of the telomeres was measured using the TeloTAGGG Telomere Length Assay kit (Roche Diagnostics Scandinavia $\mathrm{AB}$ ) according to the protocol provided by the manufacturer.

\section{Results}

\section{Flow cytometry analysis of hMSCs}

Flow cytometry analysis was used to evaluate the enrichment of a homogenous population of hMSCs, demonstrating that $96 \% \pm 2 \%$ of the cells were CD166+/CD $45-$ and $94 \% \pm 1 \%$ of the cells were CD105+/CD34-.

\section{Cell morphology}

While hESCs (Fig. 1A) exhibited their typical morphology and characteristic growth in colonies, the hES-MPs (Fig. 1B) displayed a fibroblast-like morphology characteristic of hMSCs (Fig. 1C).

\section{Global gene expression comparison}

Scatter plot analysis of the microarray data for each pairwise comparison showed that hES-MPs and hMSCs display a more narrow spatial distribution of gene expression, with
$90 \%$ of the genes displaying an FC $\leq 3$ (Fig. 2A, D). Results from the other two comparisons (hESCs vs. hES-MPs and hESCs vs. hMSCs) showed larger transcriptional differences with $25 \%$ or more of the genes with an FC $\geq 3$ (Fig. 2B-D). The Spearman correlation coefficients demonstrated a higher correlation between hES-MPs and hMSCs (0.92) than between hESCs vs. hES-MPs (0.83) and hESCs vs. hMSCs (0.79) (Fig. 2D). Hierarchial clustering of 447 genes with an FC $\geq 20$ resulted in three main groups-hESCs, hES-MPs, and hMSCs (Fig. 2E). This analysis further demonstrates that the hES-MPs and the hMSCs display a more similar expression pattern than hES-MP compared with hESCs.

In Table 1A, the expression levels of 40 genes known to be specifically expressed in hESCs is shown. Out of these genes, 27 genes were significantly downregulated during hES-MP derivation and most of the genes (32 out of 40) displayed a transcription level similar to hMSCs. Among these genes, several genes involved in the maintenance of pluripotency (POU5F1, NANOG, ZIC3, TDGF1, and LIN28) significantly decreased in expression at least 50 times during hES-MP derivation; with the exception of NANOG, no significant differences in expression of these genes were detected between hES-MPs and hMSCs. None of the markers for hESCs increased in expression during hES-MP derivation. Three genes (BRRN1, FLJ20105, and HELLS) displayed an at least 



FIG. 1. Light micrographs showing human embryonic stem cells (hESCs) (A) growing on a mouse embryonic fibroblast feeder layer (scale bar $=100 \mu \mathrm{m}$ ), and hESC-derived mesodermal progenitors (hES-MPs) (B) and human mesenchymal stem cells (hMSCs) (C) expanded on tissue culture plastic (scale bar $=10 \mu \mathrm{m}$ ). 10-fold higher expression in hES-MPs compared with hMSCs, whereas MCM10, CDC25A, and ORC1L showed a 9.7-fold, 6.1-fold, and 4.6-fold higher expression in hES-MPs compared with hMSCs.

Analyzing expression of 48 genes known to be overexpressed in hESCs compared with differentiated cell types demonstrated that 39 genes decreased in transcription during hES-MP formation (Table 1B). Within this group of genes, some additional genes of importance for pluripotency were detected as significantly downregulated during hES-MP derivation, including LEFTY1 and SOX2. None of the 48 genes known to be overexpressed in hESCs compared with differentiated cell types displayed higher expression in hESMPs compared with hESCs. Genes differentially expressed between hES-MPs and hMSCs include MCM5, which had 9.2fold higher expression in hES-MPs compared with hMSCs, and PLA2G16, displaying a higher expression in hMSCs.

Of the 30 selected genes known to be underexpressed in hESCs compared with differentiated cell types, 15 genes were induced during hES-MP derivation (Table 1C). Some of these genes include genes encoding mesodermal extracellular matrix components (COL1A1, COL1A2, COL2A1, COL3A1, COL5A1, COL5A2, COL11A1, and COL6A3) (Table $1 C)$. The majority of these genes were induced to the same level as seen in hMSCs. On the other hand, genes encoding markers for ectodemal tissues, such as keratins (KRT18, $K R T 19, K R T 7$, and KRT8) were not induced during the process of hES-MP formation.

In Table 2 (A, B), the 15 most up- and down-regulated genes per each of the 5 categories described above are listed, if existing. Several genes encoding transcription factors displayed a decreased transcription during hES-MP derivation (SIX1, PPRX1, NR2F2, BNC1, RUNX2, and BCOR). The hMSCs displayed the highest expression level of the HOX genes (HOXA9, HOXA10, HOXC6, and HOXC10), their downstream mediator EMX2 and IRX3, as well as FOS genes (FOS and FOSB). Studying genes encoding extracellular matrix components induced during hES-MP derivation, we added the following genes to the results described above: COL1A2, COL6A2, COL6A, BGN, MFAP5, FN1, and FBN1. Several genes encoding matrix proteins were thus induced during hES-MP formation; in fact, the only gene in this category that was found to have higher expression in hESCs than in hES-MPs and hMSCs was LAMA1.

For the membrane receptor category, essential receptors for mesodermal differentiation, such as TGFRB2 and $B M P R 2$, are shown to be expressed to a greater extent in hES-MPs and hMSCs compared with hESCs. Finally, genes encoding cell adhesion molecules, including the hMSCs markers CD44, CD58, CD47, and CD166 (ALCAM), were significantly induced during hES-MP derivation to a level similar to hMSCs.

In total, 9 hubs were identified among the genes induced by hES-MP derivation (PLAU, THBS1, FN1, COL1A1, COL1A2, MFS2, CD44, CDKN2A, and CAV1) (Fig. 3A). Only one hub, EWSR1, was identified among the genes repressed during this process (Fig. 3B). Hub genes with higher expression in hES-MPs compared with hMSCs include several genes composing the spindle assembly checkpoint (CDC20, AURKA, AURKB, BUB1B, NDC20, MAD2, ERCC6L, NUF2, CENPA, AP14, SPC24, D40, SPC25, CENPM, MLF1IP, ZWINT, CENPF, CDCA8, NEK2, and 

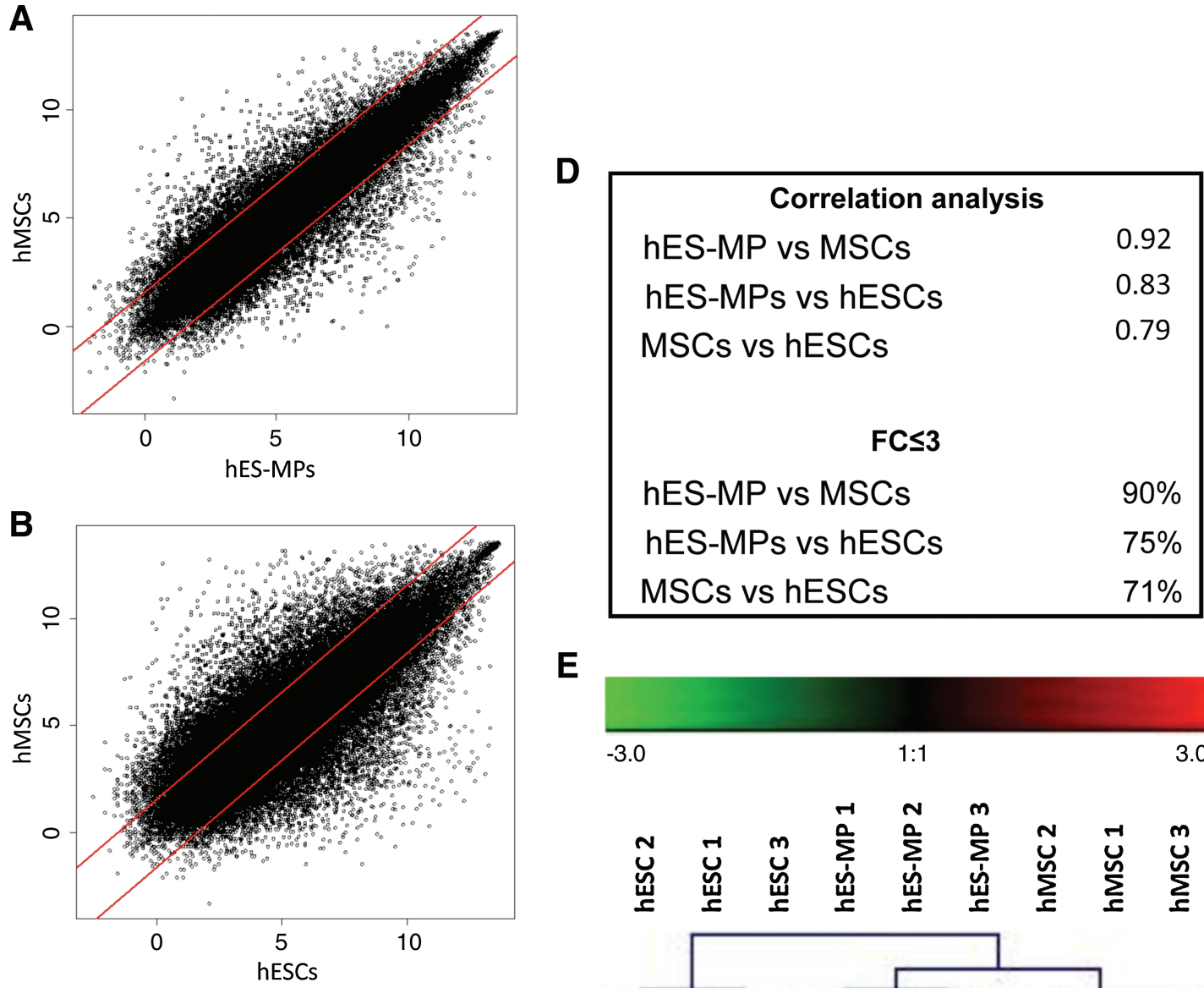

$\mathbf{E}$
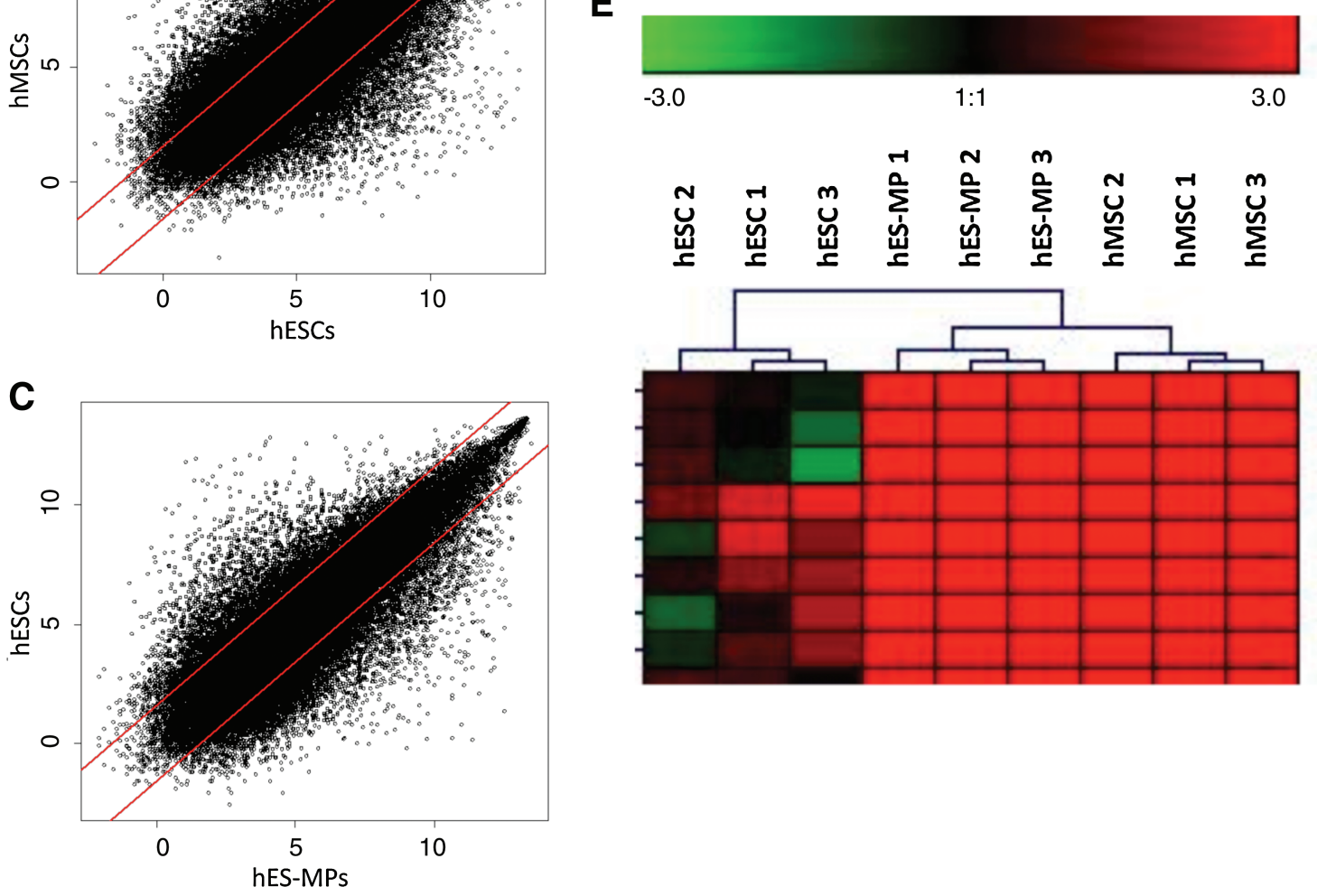

FIG. 2. Scatter plots (A-C), where genes within the lines indicate a fold change (FC) of less than \pm 3 . Summary of the scatter plots and Spearman correlation analysis (D). Hierarchical clustering of genes with an FC $\geq 20$ (E). Color images available online at www.liebertonline.com/ten.

CCNB1) (Fig. 3C). Only one hub gene, JUN, was identified among the genes with higher expression in hMSCs than hES-MPs (Fig. 3D).

\section{Real-time PCR}

Microarray results for TDGF, TGF- $\beta 2 R, R U N X 2, C O L 1 A 1$, $L H X 8$, and $B M P 2 R$ were verified using real-time PCR, which corroborated the microarray results in all cases except for $B M P 2 R$, in which no significant differences could be detected between the three different cell types studied (Fig. $4 \mathrm{~A}-\mathrm{F})$.

\section{Flow cytometry}

The flow cytometry analysis confirmed the microarray results for adhesion proteins characteristic for hMSCs (CD44, CD58, CD166, and CD47), demonstrating that the undifferentiated hESCs displayed significantly lower expression of these four markers compared with the hMSCs and hES-MPs, 


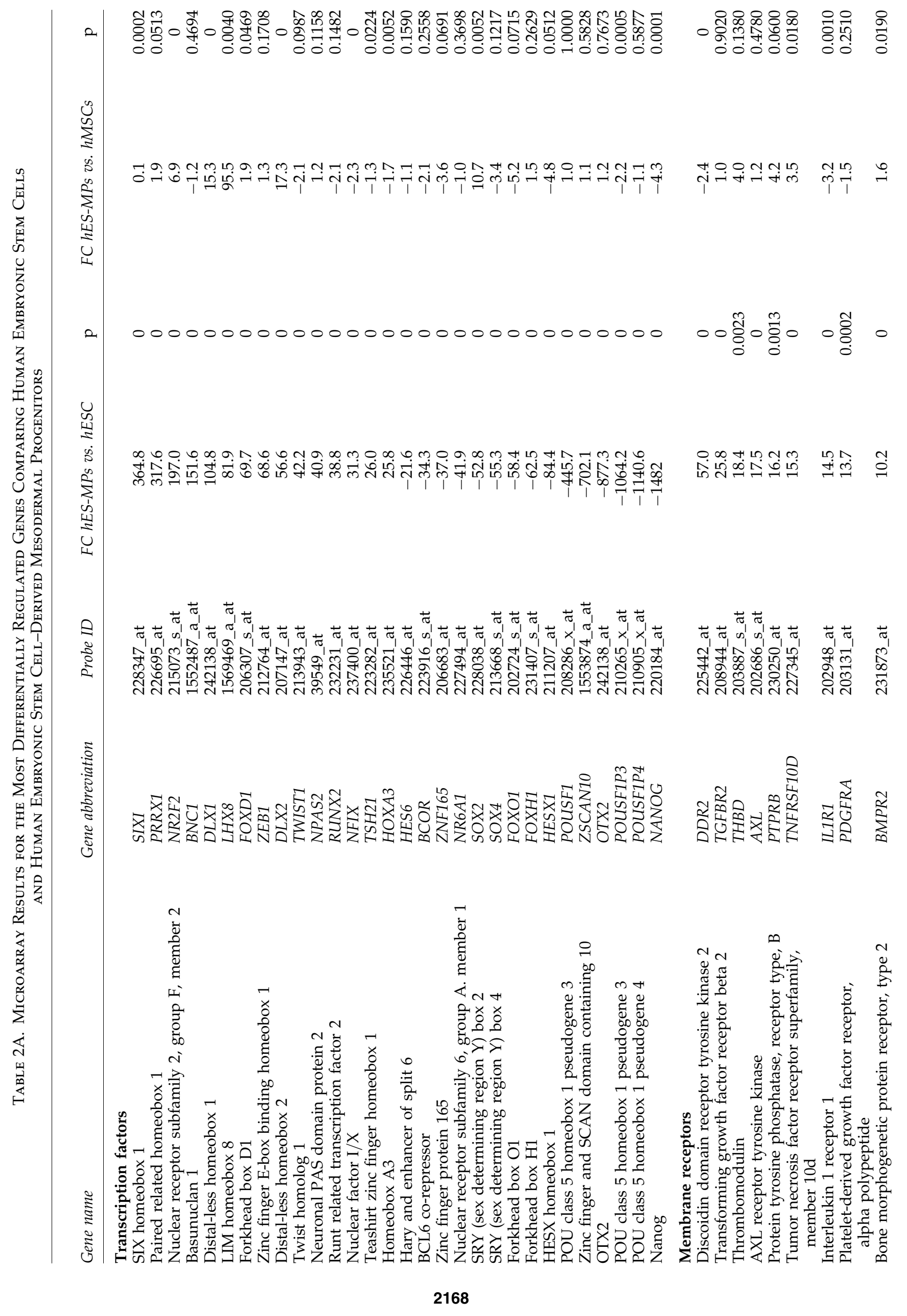




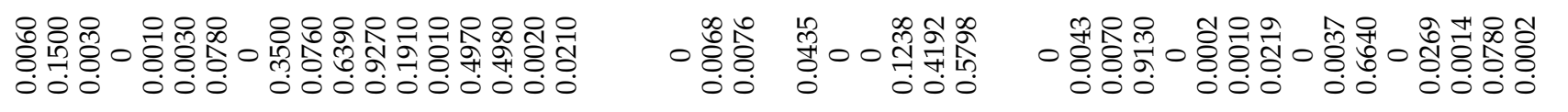

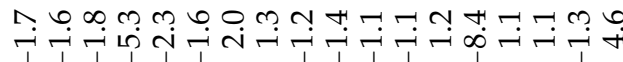

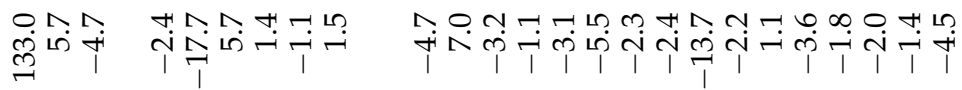

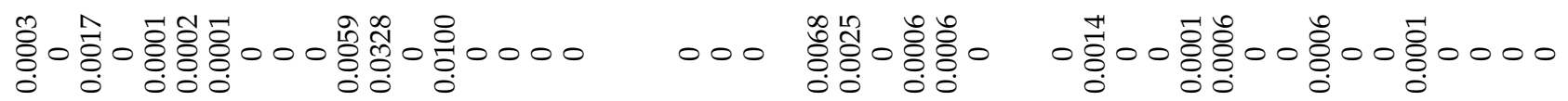



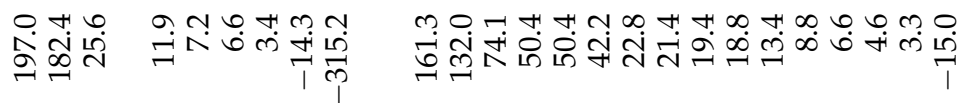

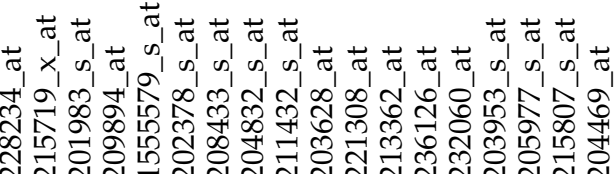

$\pi^{\pi}, \frac{\pi}{4}$

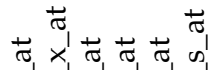



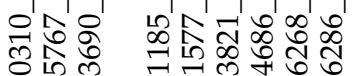

ros

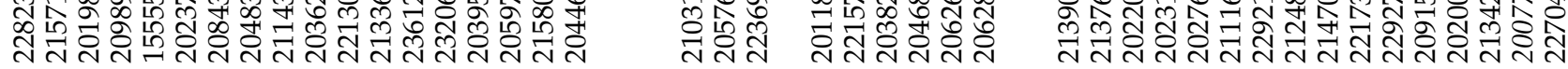

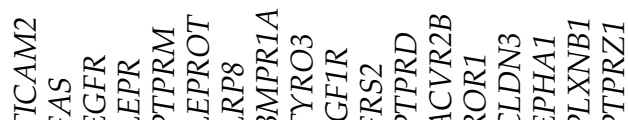

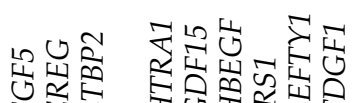

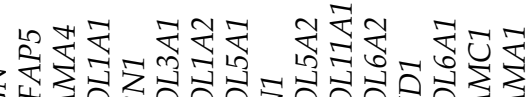

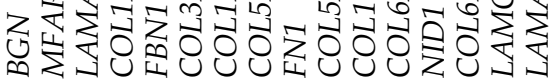
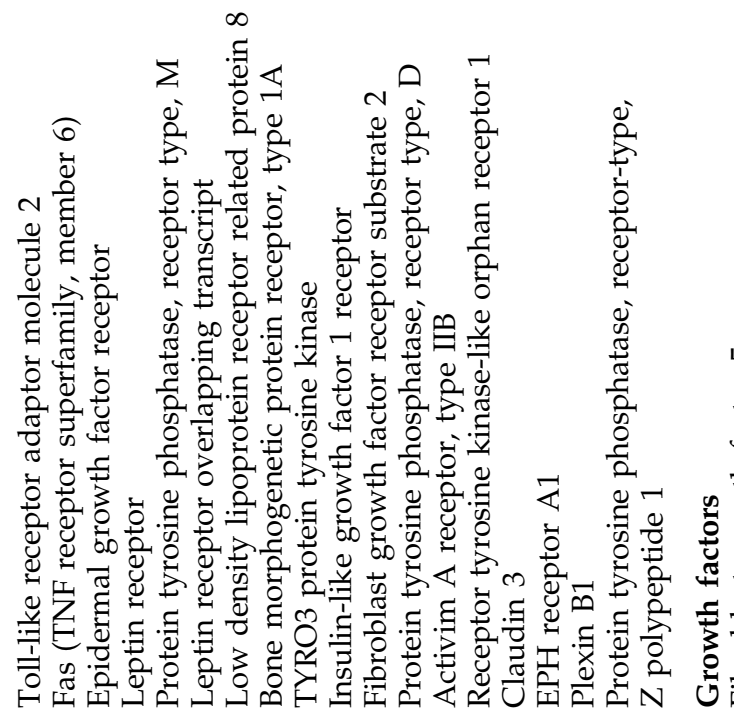

10
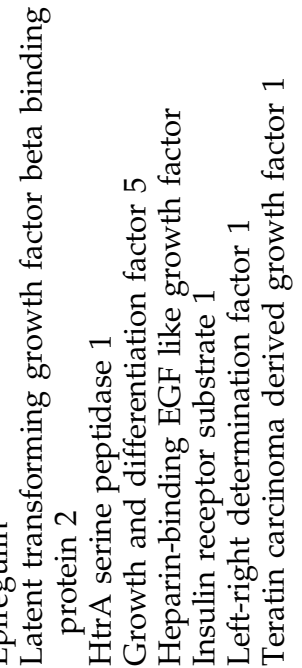

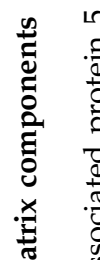

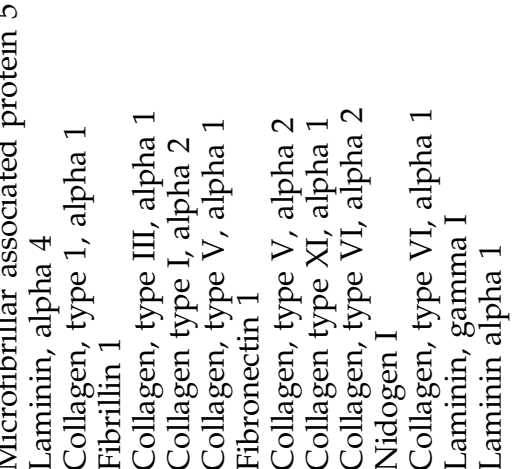




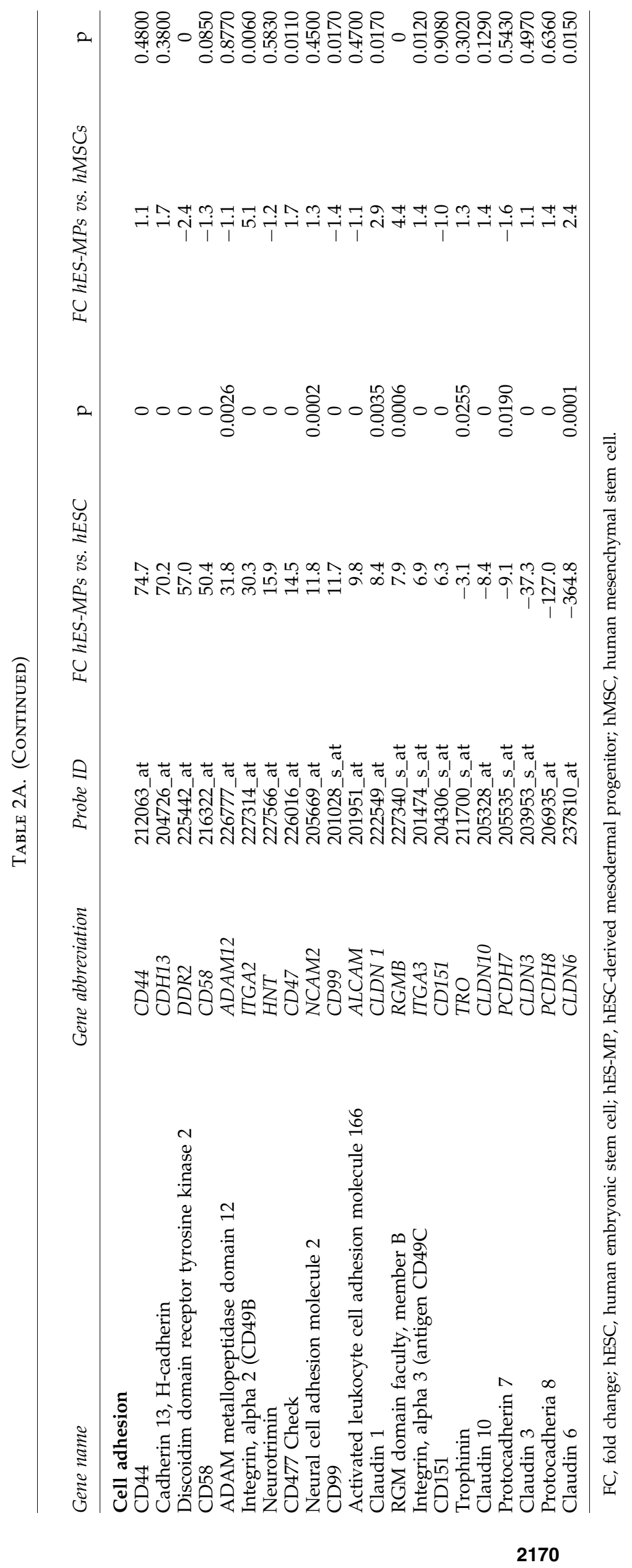









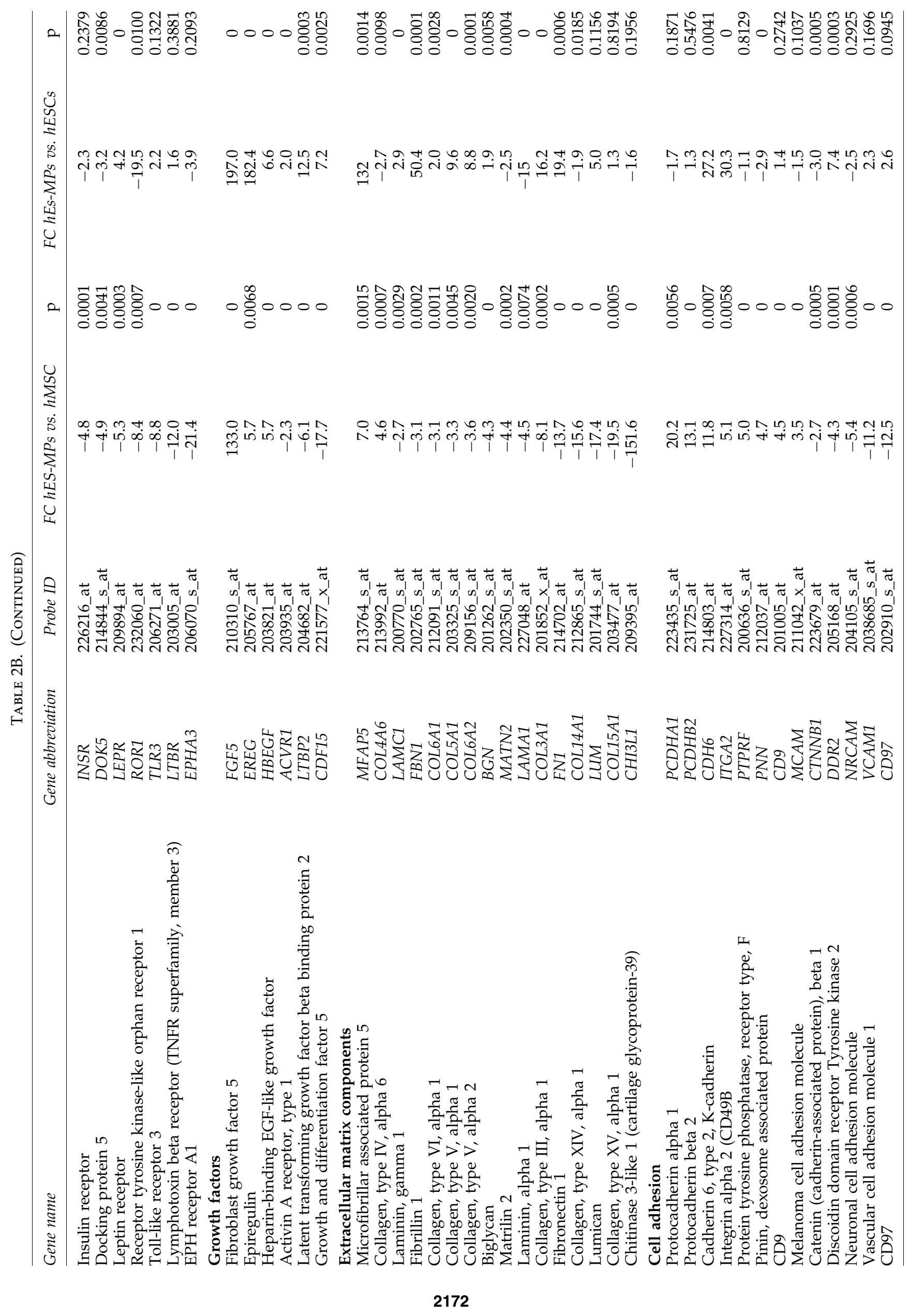


A

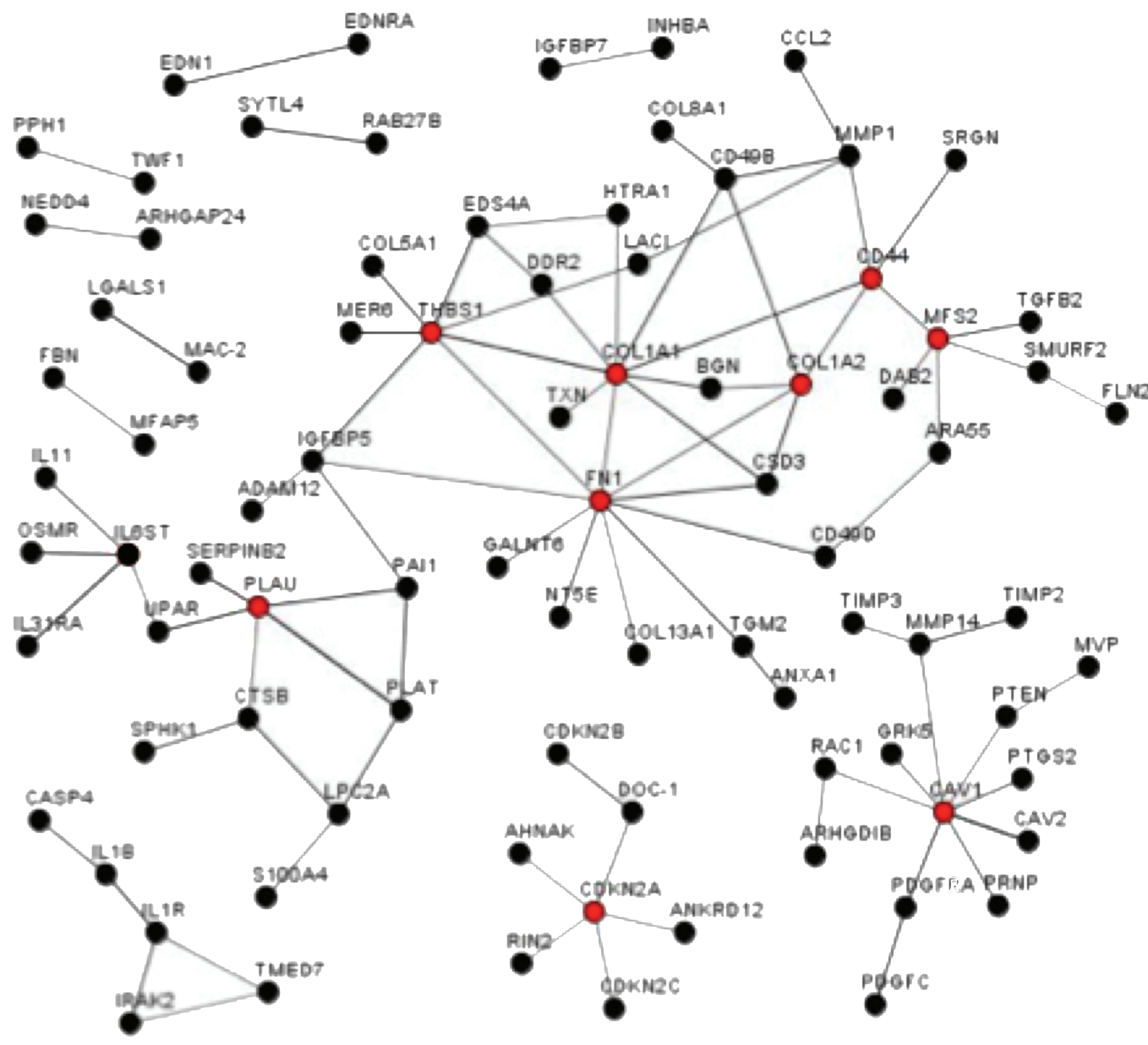

B

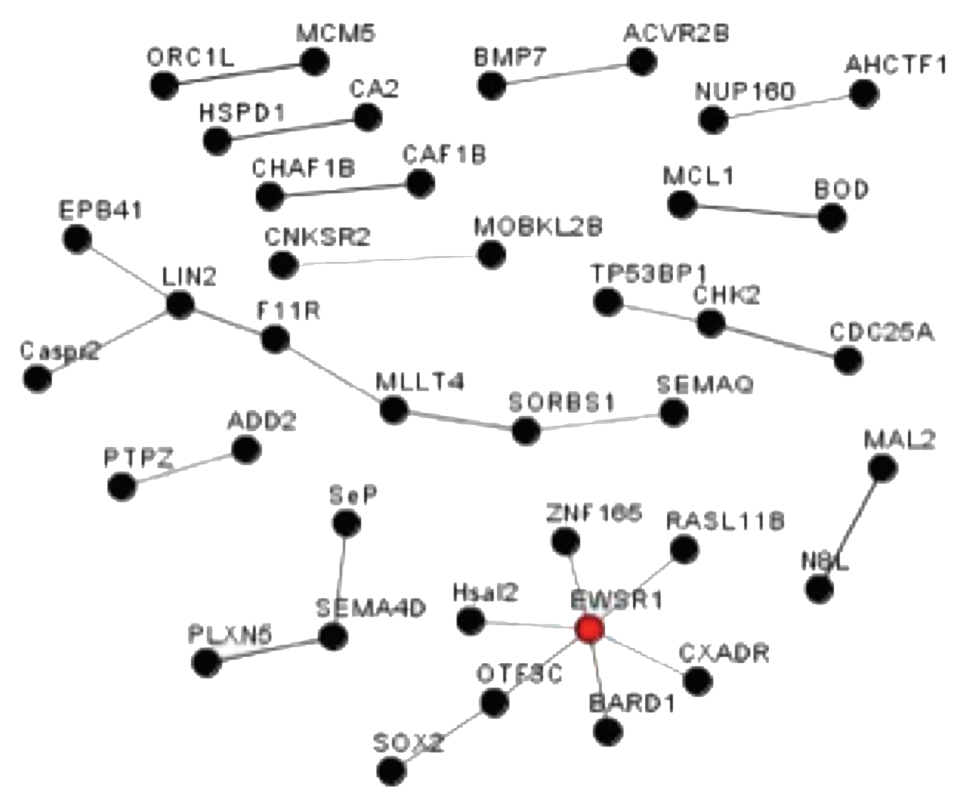

FIG. 3. Hub protein network of genes induced (A) and repressed (B) during hES-MPs derivation, as well as genes with an increased (C) and decreased (D) expression in hES-MPs compared with hMSCs with at least a 10-FC in expression. Proteins are identified as hubs if they have at least five experimentally determined protein interactions among the products of the upregulated genes. Color images available online at www.liebertonline.com/ten. 
C

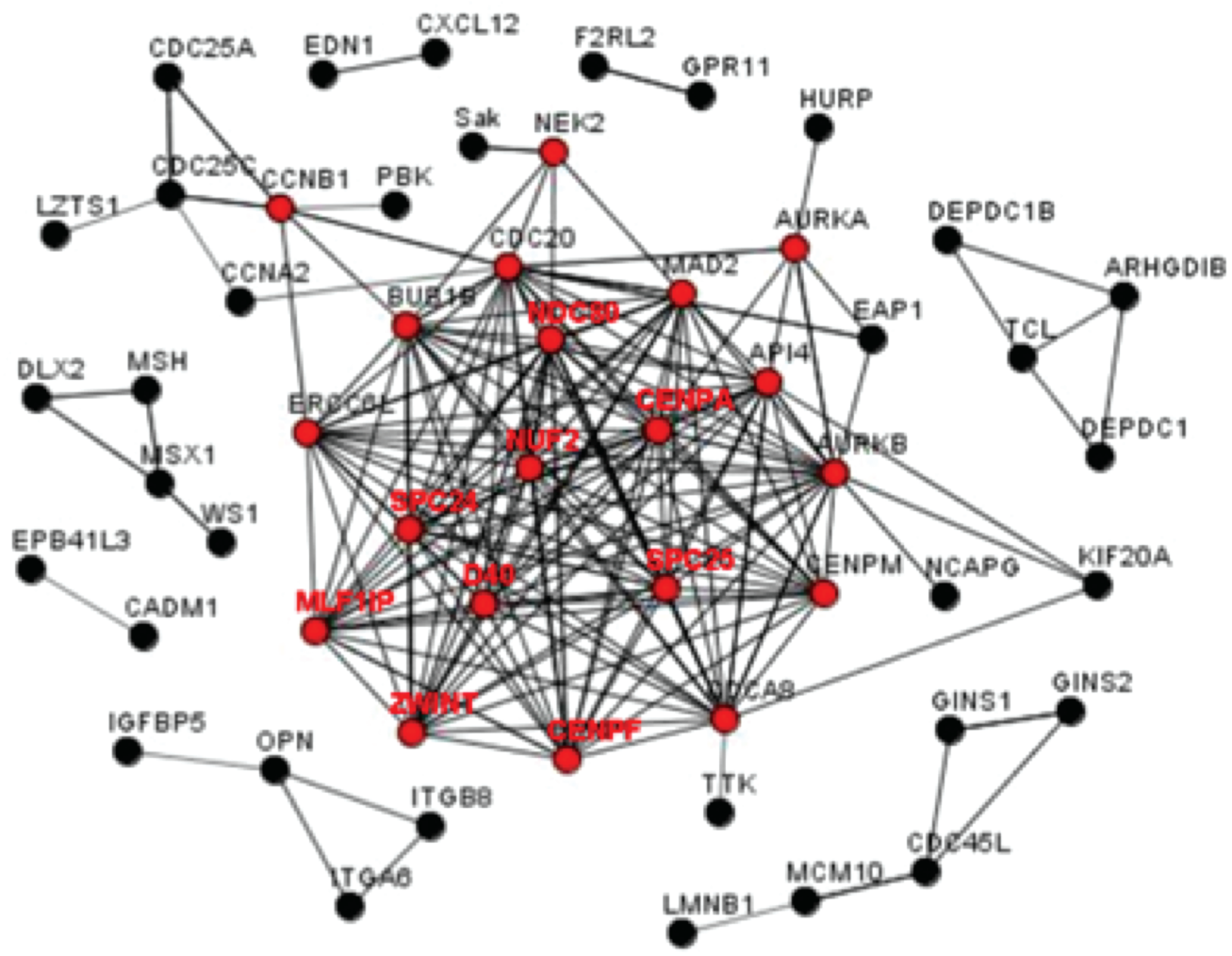

D

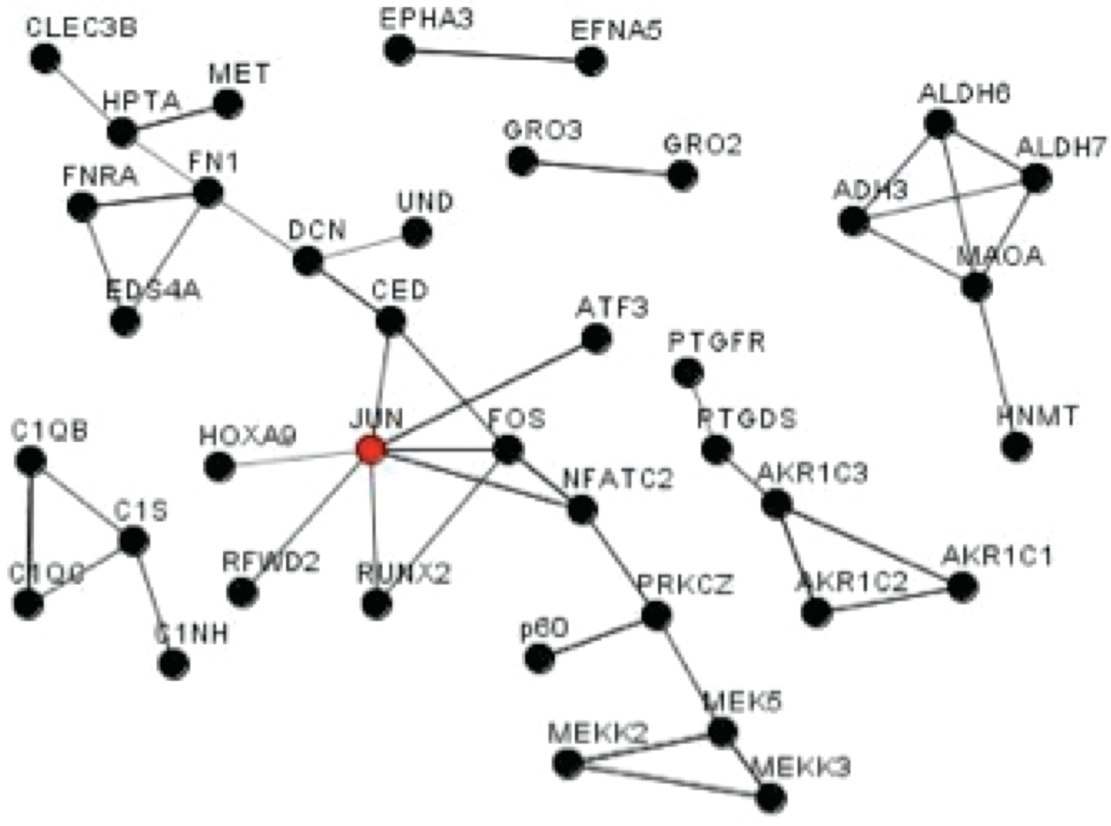

FIG. 3. (Continued).

which showed a comparable expression for all of the markers studied (Fig. 4G-J).

\section{Immunohistochemistry}

Immunohistochemistry demonstrated that only hESCs were positively stained for OCT4 and NANOG as shown in Figure $4(\mathrm{~K}, \mathrm{~N})$, whereas hES-MP cells $(\mathrm{L}, \mathrm{O})$ and hMSCs $(\mathrm{M}$, $\mathrm{P})$ were negative for both markers.

\section{Proliferation ability}

Throughout the proliferative assay, the hES-MPs displayed a significantly higher number of cell doublings per time period compared with the hMSCs (Fig. 5A). Around passages $8-10$, an initial decline in the proliferative potential of hMSCs was detected. This was followed by a more or less ceased proliferation after passage 20. The hESMPs, on the other hand, retained their high proliferative 
A



C



E

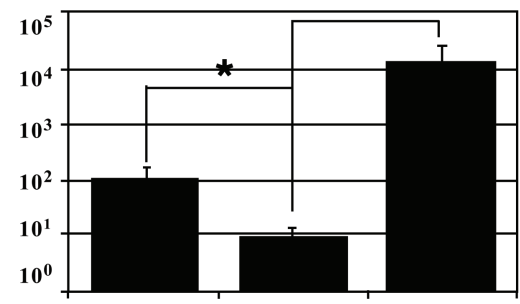

hESChMSChES-MP


B

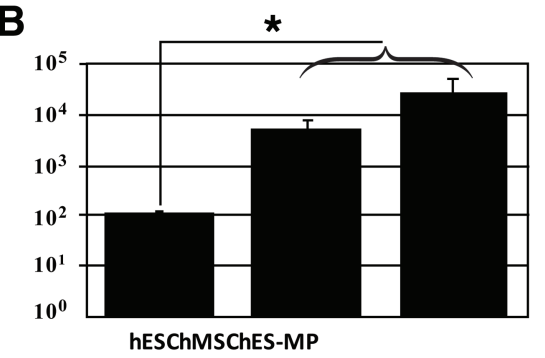

D

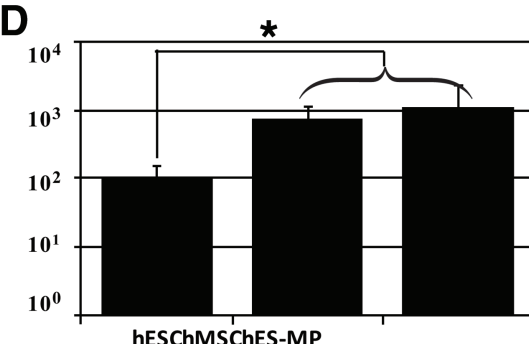

$\mathbf{F}$

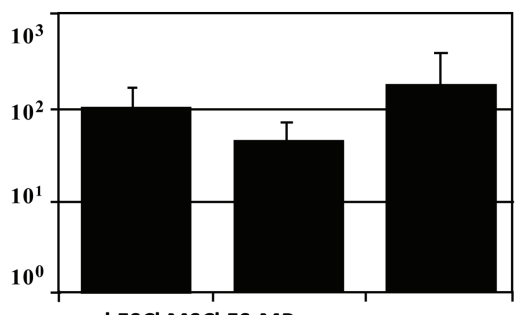

hESChMSChES-MP

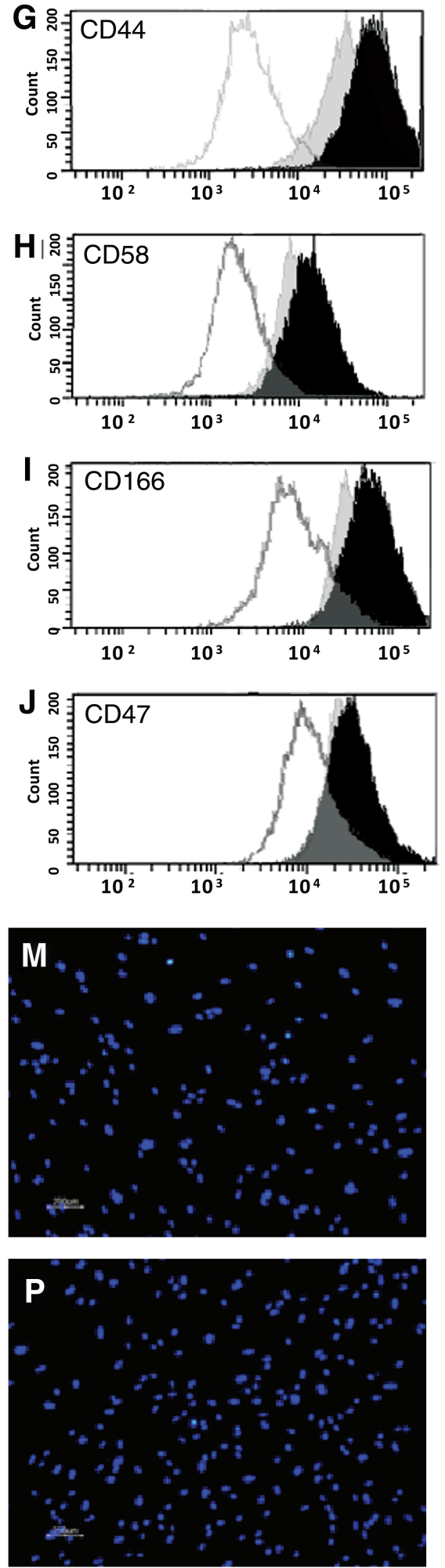

FIG. 4. Verification of microarray results using quantitative RT-polymerase chain reaction analysis for TDGF1 (A), TGF- $\beta 2 R$ (B), RUNX2 (C), COL1A1 (D), LHX8 (E), and BMP2R (F) (differences were accepted to be statistically significant at $p \leq 0.05$ $\left.{ }^{*}\right)$ ). Flow cytometry analysis of CD44 (G), CD58 (H), CD166 (I), and CD47 (J) for hESCs (white), hES-MPs (black), and hMSCs (gray). Expression of OCT4 $(\mathbf{K}-\mathbf{M}$ : scale bar $=250 \mu \mathrm{m})$ and NANOG $(\mathbf{N}-\mathbf{P}$ : scale bar $=250 \mu \mathrm{m})$ in hESCs $(\mathbf{K}, \mathbf{N})$, hES-MPs $(\mathbf{L}, \mathbf{O})$, and hMSCs $(\mathbf{M}, \mathbf{P})$. Color images available online at www.liebertonline.com/ten. 
A

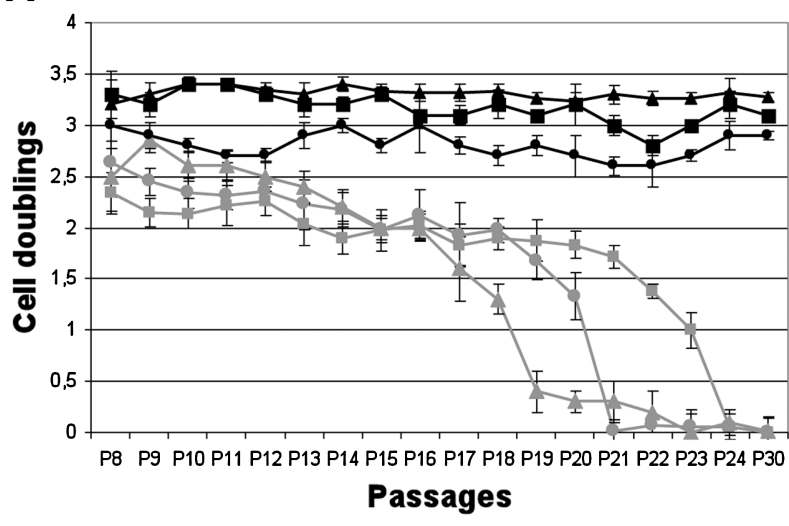

H

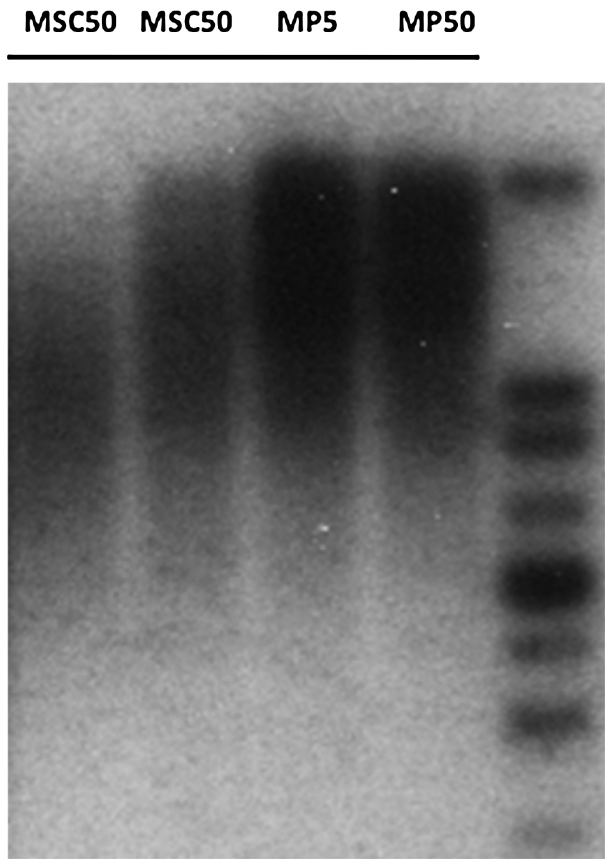

21.2

8.6

I

7.4

6.1

5.0

4.2

4.2

3.5

2.7
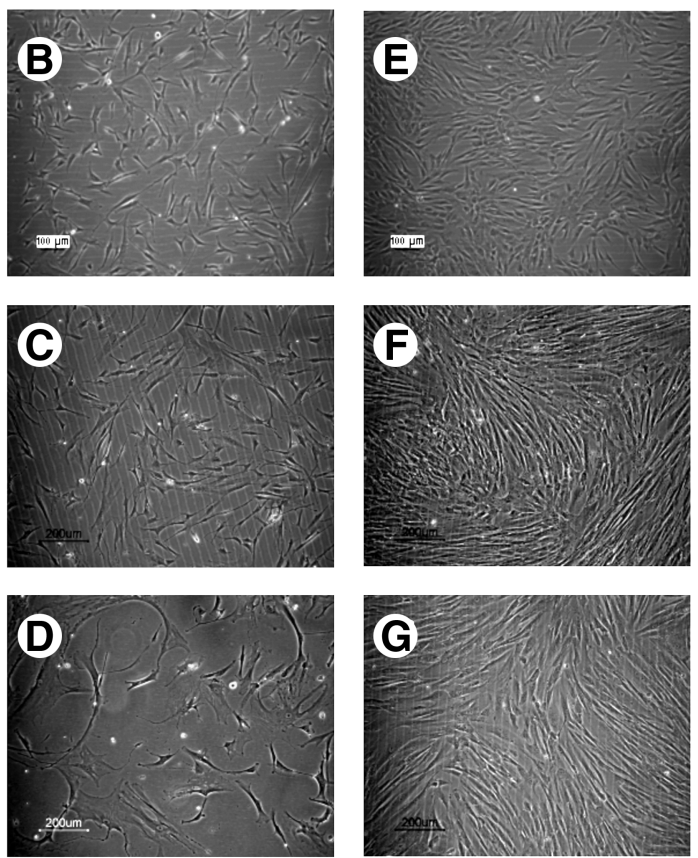

Telomerase Activity

1.40

1.20

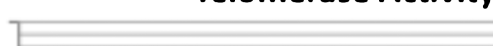

1.00

0.80

0.60

0.40

0.20

0.00

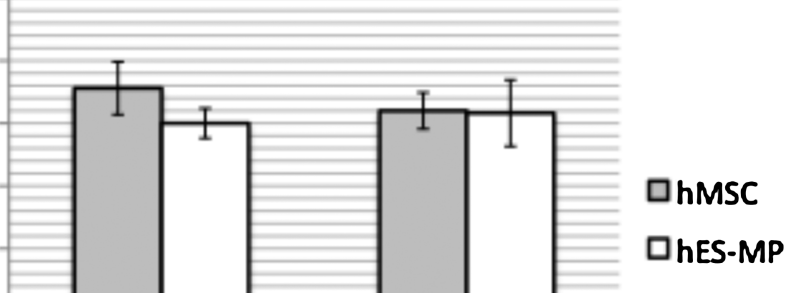

FIG. 5. Cell doublings of hMSCs and hES-MPs (A). Light micrographs of hMSCs (B-D) and hES-MPs (E-G) at passage 5 (B, E: scale bar $=100 \mu \mathrm{m}), 10(\mathbf{C}, \mathbf{F}$ : scale bar $=200 \mu \mathrm{m})$, and $20(\mathbf{D}$, G: scale bar $=200 \mu \mathrm{m})$. Telomere length $(\mathbf{H})$ and telomerase activity (I) of both cell types at population doubling 5 and 50 (PD5 and PD50).

capacity for the whole duration of the test (up to passage 30$)$.

\section{Telomerase activity and telomere length}

Both hES-MPs and hMSCs at PD 5 and 50 showed a similar level of telomerase activity (Fig. 5I). In contrast, the telomeric repeat fragments were longer for hES-MPs compared with hMSCs at both passages investigated (Fig. $5 \mathrm{H}$ ).

\section{HLA expression}

Flow cytometry analysis for immunological markers demonstrated that both hMSCs and hES-MPs were found to be negative for CD80 (Fig. 6A, I) and CD86 (Fig. 6B, J). Expression of these two markers was further not affected by
IFN- $\gamma$ treatment in either hMSCs (Fig. 6E, F) or hES-MPs (Fig. 6M, N). On the other hand, all hMSCs were positive for HLA-ABC (Fig. 6C) and about half of the hMSC population was also positive for HLA-DR (Fig. 6D). Expression of these two markers further increased after IFN- $\gamma$ treatment (Fig. 6G, H). In contrast, the hES-MPs displayed somewhat lower expression of HLA-ABC compared with the hMSCs (Fig. 6K) and were negative for HLA-DR (Fig. 6L). Expression of HLA-ABC after IFN- $\gamma$ treatment of hES-MPs (Fig. $6 \mathrm{O})$ was similar to that of IFN- $\gamma$-treated hMSCs. A small population of hES-MPs became positive for HLA-DR after IFN- $\gamma$ treatment (Fig. 6P), but the expression level is significantly lower compared with that of the hMSCs. The same results were detected for cells in high passage (data not shown). 
CD80
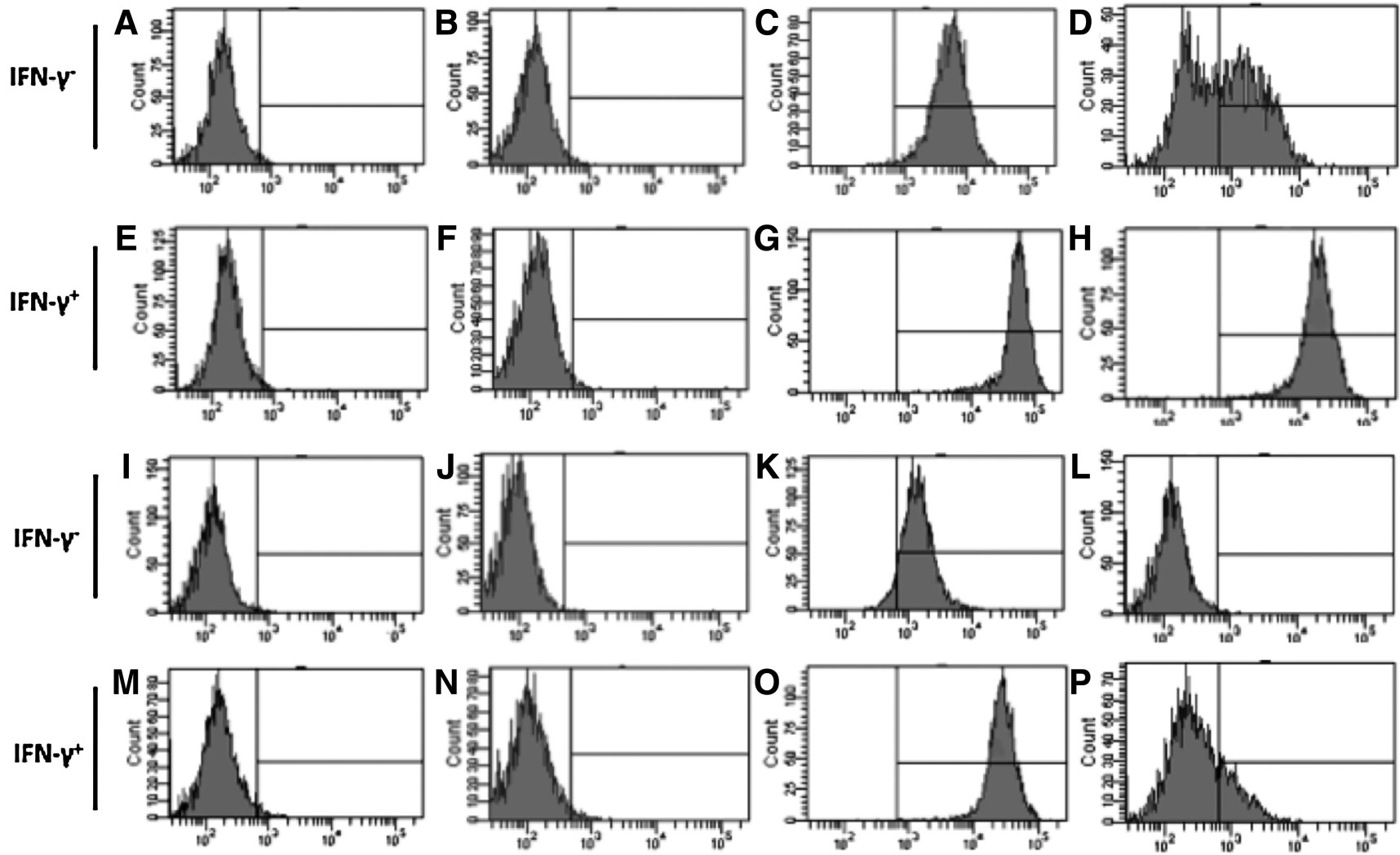

FIG. 6. Flow cytometry analysis of CD80 (A, E, I, M), CD86 (B, F, J, N), HLA-ABC (C, G, K, O), and HLA-DR (D, H, L, P) for hMSCs (A-D) and hES-MPs (I-L). Analyses of the same markers after interferon- $\gamma($ IFN- $\gamma)$ treatment for hMSCs (E-H) and hES-MPs (M-P).

\section{Discussion}

The main questions addressed in this study were how the transcriptome is affected by the process of hES-MP derivation, and how distinct or equivalent cell types the hESCs and the hESC-derived hES-MPs are. Our results from hierarchical cluster analysis, scatter plot analysis, and Spearman correlation analysis all demonstrated that our straightforward protocol for derivation of hES-MPs results in a cell line highly similar to hMSCs, which is in accordance with earlier results from our laboratory. ${ }^{7}$ These transcriptional alterations occurring during hES-MP derivation result in a significantly decreased transcription of genes known to be specifically expressed in hESCs. For instance, the OCT family of genes (POU5F1, POU5F1P3, and POU5F1P4) as well as NANOG are essential transcription factors involved in the maintenance of pluripotency with exclusive expression in ES cells. ${ }^{18-21}$ In accordance, $S O X 2$, which has been found to form a complex with OCT4 and bind to the NANOG promoter in hESCs, ${ }^{22}$ was shown to be highly expressed in hESCs and down-regulated during hES-MP derivation to a level similar that in hMSCs. A similar expression pattern was observed for other genes important for pluripotency, including TDGF1, LIN28, GDF3, $A L P L, G A L, D P P A 4$, GABRB3, and ZIC3. ${ }^{15,23-28}$ Repression of these genes detected during hES-MP derivation thus provides the molecular evidence for the lineage commitment detected in hES-MPs compared with hESCs. ${ }^{7}$

Pluripotency is strongly associated with teratoma formation, and one of the most well-known genes to induce these processes is TDGF1. ${ }^{29,30}$ The same expression pattern was detected for EPHA1, which is overexpressed in many tumors, and DNMT3B, which is known to inhibit tumor suppressor genes. ${ }^{31,32}$ Another important gene for tumor development is $p 53$, whose inactivation is a common feature in many tumors and whose transcription is induced by binding of NR2F2 to the p53 promoter. ${ }^{33}$ Significantly increased expression of NRF2F during hES-MP formation, as well as altered expression of the p53-associated genes LTBP2 and TFAP2A, is thus yet another way for the hES-MP cells to decrease their tumorigenicity. ${ }^{34,35}$ Identified hub genes induced by hES-MP derivation include THBS1, known to inhibit angiogenesis, as well as the tumor suppressor CDKN2A ( $p 16$ ) and CAV1. ${ }^{36,37}$ The tumor-associated gene EWSR1 was identified as the only hub for genes with a reduced expression pattern during the process of hES-MP derivation. This study thus provides the molecular clues for the lack of teratoma formation detected in the hES-MPs, which is a prerequisite for possible future clinical applications. 
With regard to genes associated with proliferation, a panel of such genes (HELLS, CDC25A, MCM5, FGF5, BUB1, and ORC1L) was significantly downregulated during hES-MP derivation, but hES-MPs still had significantly higher expression of these genes compared with hMSCs. HELLS is ubiquitously expressed in rapidly dividing cells, ${ }^{38,39}$ and targeted disruption of HELLS leads to increased replicative senescence along with altered gene expression pattern, particularly the senescence-related genes such as CDKN2A and BMI1. ${ }^{40}$ Moreover, CDKN2A is one of the hub genes identified in the process of hES-MP derivation as discussed above. The hES-MPs further displayed significantly higher expression of MCM10, MCM5, and ORC1L required for DNA replication, the mitogen FGF5, and CDC25A known to accelerate S-phase entry. ${ }^{41-44}$ Another pathway inducing proliferation activated during hES-MP derivation was signaling via EGF, and increased expression of $H B E G F$, the receptor $E G F R$, and its ligand EREG was detected. ${ }^{45}$ Other signaling pathways seem to regulate hMSC proliferation, including the FOS family of transcription factors inducing quiescent cells to reenter the cell cycle. ${ }^{46}$ This protein together with $J U N$, which was identified as a hub gene with increased expression in hMSCs, forms the AP- 1 complex. ${ }^{47}$ The expression pattern of genes in hES-MPs resulting in increased proliferative potential is in line with the high proliferative capacity of these cells (shorter PD time and retained proliferative potential over extended time) compared with hMSCs demonstrated in this study. Decreased proliferative potential of hMSCs during long-term in vitro culture has earlier been demonstrated and has to some extent been explained by the decreasing telomere length. ${ }^{48}$ The high proliferative potential of the hES-MPs is further in accordance with the presence of longer telomeres compared with the hMSCs, while no differences in telomerase activity was detected. The differences in telomere length observed between hES-MPs and hMSCs may be associated with the intrinsic different source of the two cell types. Isolation from adult donors implies that hMSCs have undergone a higher number of cell divisions, resulting in the shortening of their telomeric sequences. hMSCs displayed increased telomeric length at PD50, suggesting that other mechanisms, known as alternative lengthening of telomeres, which are recognized to be involved in oncogenic transformation, ${ }^{49}$ may become activated in hMSCs after protracted expansion. From a different standpoint, these data can be interpreted as results of natural selections, where cells carrying an advantageous ability to keep their telomeric sequences take over the culture and eventually represent the only population of cells able to proliferate for long time. The higher proliferative potential of the hES-MPs provides these cells with a great advantage over hMSCs for bulk production of cells for therapy and tissue engineering applications.

During each cell division cycle, the newly duplicated chromosomes must be distributed evenly into the new cells so that each cell receives exactly one copy of each chromosome. Errors in this process result in aneuploidy that is manifested in genetic disorders and tumors. Accurate sister chromatid segregation relies on the attachment and alignment of chromosomes to the mitotic spindle. This process is controlled by the spindle assembly checkpoint, which restrains cells from entering anaphase until all replicated chromatids have formed proper attachments to a functional bipolar spindle. Several genes encoding proteins constituting this complex, such as CDC20, MAD2, BUB1B, NDC80, NUF2, CENPA, ERCC6L, SPC24, MLF1IP, AURKB, D40, SPC25, CENPM, ZWINT, and CDCA8, were identified as hub genes with significantly increased expression in hES-MPs compared with hMSCs (for review, see Bharadwaj and $\mathrm{Yu}^{50}$ ). Inactivation of certain checkpoint genes results in early embryonic lethality, high levels of chromosome mis-segregation, and apoptosis. ${ }^{51}$ The identification of these hub genes overexpressed in hES-MPs demonstrates a strong control function of mitosis important to reduce the risk of tumor formation.

Analyzing expression of 48 genes overexpressed in hESCs compared with differentiated cells demonstrated that hESMPs derivation results in a more differentiated cellular phenotype consistent with its lineage commitment discussed above and increased expression of markers downregulated in hESCs compared with differentiated cell types. hES-MP derivation did not result in altered expression of genes encoding keratins (KRT18, KRT19, KRT7, and KRT8) demonstrating lack of differentiation into the ectodermal lineage. Decreased expression of several claudins (CLDN3, CLDN6, CLDN8, CLDN10, and CYP26A1) known to be important for retinoic acid metabolism during endodermal differentiation and the early neural marker CRMP1 demonstrates lack of differentiation into the endodermal lineage during hES-MP derivation. ${ }^{52,53}$ The above results are in accordance with the findings previously observed, where hES-MPs were found to be negative for markers typical of the ectodermal and endodermal lineage. ${ }^{7}$ In contrast, a panel of genes encoding collagen and other genes characteristic for mesodermal tissues (COL1A1, COL1A2, COL3A1, COL5A1, COL11A1, COL6A1, COL6A2, DDR2, BGN, FN1, FBN1, and MFAP5) and proteins important for cell-to-cell contact or attaching cells to the extracellular matrix (CD44, CD58, CD47, and CD166) were induced by hES-MP derivation to a level similar that in hMSCs. ${ }^{54}$

Other signs of lineage commitment into the mesodermal lineage include increased expression of genes encoding membrane receptors responsive to growth factors inducing mesodermal differentiation (TGFBR2 and BMPR2), ${ }^{55}$ and overexpression of $R U N X 2^{56}$ and TFAP $2 A,{ }^{57}$ known to be expressed during osteogenic differentiation. This differentiation into the mesodermal lineage detected might be due to significantly decreased expression of LEFTY1 detected during hES-MP derivation. Lefty 1 is known to block Nodal signaling by binding Nodal and its coreceptors such as TDGF1. This binding prevents the assembly of an active Nodal/Activin receptor complex, resulting in inhibited mesodermal development. ${ }^{58,59}$ The only gene coding for an extracellular matrix component that displayed higher expression in hES cells than in hES-MPs was LAMA1. This gene is involved in embryonic patterning and is one of the few essential extracellular matrix proteins in early embryogenesis. ${ }^{60}$ It is further significantly downregulated upon development and ES cell differentiation, which is consistent with its decreased expression during hES-MP formation. ${ }^{61}$ Induction of these mesodermal markers by hES-MP derivation to the same extent as seen in hMSCs demonstrates the potential of the hES-MP cells in tissue engineering of mesodermal tissues. ${ }^{62}$ These data further corroborate previous results demonstrating the in vitro and 
in vivo differentiation of hES-MPs into tissues of the mesodermal lineage. ${ }^{7}$

The most overexpressed transcription factors detected in hMSCs compared with hES-MPs were HOXA9, HOXA10, and their downstream effector IRX3, whose expression pattern indicates a suppression of erythroid differentiation in hMSCs, reflecting the origin of these cells and the need for this system to maintain the cells undifferentiated. ${ }^{63}$ On the other hand, the most highly upregulated transcription factor in hES-MPs compared with hMSCs was LHX8, which is essential for tissue patterning and differentiation during embryogenesis. ${ }^{64}$ Other transcription factors upregulated in hES-MPs compared with hMSCs were SALL1, PAX3, MSX1, DLX1,DLX2, and LZTS1. SALL1 is known to play a function in limb cartilage morphogenesis, ${ }^{65}$ while $P A X 3$ promotes myogenic differentiation during vertebrate development. $^{66}$ High expression of DLX1, DLX2, and MSX1, supporting craniofacial development and osteogenesis, ${ }^{67,68}$ underscores the potential of hES-MPs for mesodermal tissue engineering.

Increased expression of the tumor suppressor gene LZTS1 in hES-MPs compared with hMSCs may represent an ideal characteristic for clinical applications of these cells. ${ }^{69-71}$

Most of the extracellular matrix components retrieved when comparing hES-MPs and hMSCs displayed a significant upregulation in hMSCs, indicating a more adult phenotype of the hMSCs. In relation to this assumption, the majority of these genes were further downregulated in hESCs compared with hES-MPs, suggesting that hES-MPs may represent an intermediate differentiation state between embryonic and adult stem cells.

The immunological profile of the hES-MPs is highly important for their possible future use in tissue engineering and cell therapy. hES-MPs displayed somewhat lower expression of HLA-ABC compared with hMSCs and significantly lower expression of HLA-DR. Transplantation of an allograft elicits a cascade of host responses in vivo, including secretion of IFN- $\gamma$, one of the most potent inflammatory cytokines, which further is known to stimulate expression of HLA molecules. $^{72}$ The significantly lower induction of HLA-DR in hESMPs, as opposed to the response in hMSCs, demonstrates that hES-MPs are more immuno-privileged than the hMSCs, and therefore represent a suitable alternative for in vivo applications.

\section{Conclusion}

As far as we know, this is the first comprehensive study reporting the profound transcriptional changes occurring during hES-MP derivation, resulting in a gene expression profile highly similar to that of hMSCs. These results, in combination with the immunological properties of the hESMPs reported in this study and the significantly increased proliferative potential of these cells compared with hMSCs, demonstrate that hES-MPs represent a valuable alternative to hMSCs in tissue engineering applications. This data set will also be a valuable resource to the research community to distinguish hES-MPs from hESCs.

\section{Acknowledgment}

We sincerely thank Helena Brisby for providing bone marrow samples, and Gunilla Caisander and Annelie Wi- gander for excellent technical assistance with the immunohistochemical analysis. We acknowledge BIOMATCELL VINN Excellence Center of Biomaterials and Cell Therapy, Region Västra Götland, Swedish Research Council (K200952X-09495-22-3 and 2005-7544) and JOIN(ed)T Marie Curie Action for the financial support of the study.

\section{Disclosure Statement}

No competing financial interests exist.z

\section{References}

1. Tapp, H., Hanley, E.N., Jr., Patt, J.C., and Gruber, H.E. Adipose-derived stem cells: characterization and current application in orthopaedic tissue repair. Exp Biol Med (Maywood) 234, 1, 2009.

2. Matsumoto, T., Kuroda, R., Mifune, Y., Kawamoto, A., Shoji, T., Miwa, M., Asahara, T., and Kurosaka, M. Circulating endothelial/skeletal progenitor cells for bone regeneration and healing. Bone 43, 434, 2008.

3. Granero-Molto, F., Weis, J.A., Longobardi, L., and Spagnoli, A. Role of mesenchymal stem cells in regenerative medicine: application to bone and cartilage repair. Expert Opin Biol Ther 8, 255, 2008.

4. Jukes, J.M., Both, S.K., Leusink, A., Sterk, L.M., van Blitterswijk, C.A., and de Boer, J. Endochondral bone tissue engineering using embryonic stem cells. Proc Natl Acad Sci USA 105, 6840, 2008.

5. Ringe, J., Kaps, C., Burmester, G.R., and Sittinger, M. Stem cells for regenerative medicine: advances in the engineering of tissues and organs. Naturwissenschaften 89, 338, 2002.

6. Heins, N., Englund, M.C., Sjöblom, C., Dahl, U., Tonning, A., Bergh, C., Lindahl, A., Hanson, C., and Semb, H. Derivation, characterization, and differentiation of human embryonic stem cells. Stem Cells 22, 367, 2004.

7. Karlsson, C., Emanuelsson, K., Wessberg, F., Kalic, K., Axell, M.Z., Eriksson, P.S., Lindahl, A., Hyllner, J., and Strehl, R. Human embryonic stem cell-derived mesenchymal progenitors-potential in regenerative medicine. Stem Cell Res 3, 39, 2009.

8. Xu, C., Jiang, J., Sottile, V., McWhir, J., Lebkowski, J., and Carpenter, M.K. Immortalized fibroblast-like cells derived from human embryonic stem cells support undifferentiated cell growth. Stem Cells 22, 972, 2004.

9. Barberi, T., Willis, L.M., Socci, N.D., and Studer, L. Derivation of multipotent mesenchymal precursors from human embryonic stem cells. PLoS Med 2, e161, 2005.

10. Lian, Q., Lye, E., Suan Yeo, K., Khia Way Tan, E., SaltoTellez, M., Liu, T.M., Palanisamy, N., El Oakley, R.M., Lee, E.H., Lim, B., and Lim S.K. Derivation of clinically compliant MSCs from CD105+, CD24- differentiated human ESCs. Stem Cells 25, 425, 2007.

11. Olivier, E.N., Rybicki, A.C., and Bouhassira, E.E. Differentiation of human embryonic stem cells into bipotent mesenchymal stem cells. Stem Cells 24, 1914, 2006.

12. Stojkovic, P., Lako, M., Stewart, R., Przyborski, S., Armstrong, L., Evans, J., Murdoch, A., Strachan, T., and Stojkovic, M. An autogeneic feeder cell system that efficiently supports growth of undifferentiated human embryonic stem cells. Stem Cells 23, 306, 2005.

13. Karlsson, C., Brantsing, C., Svensson, T., Brisby, H., Asp, J., Tallheden, T., and Lindahl, A. Differentiation of human mesenchymal stem cells and articular chondrocytes: 
analysis of chondrogenic potential and expression pattern of differentiation-related transcription factors. J Orthop Res 25, 152, 2007.

14. Camon, E., Magrane, M., Barrell, D., Lee, V., Dimmer, E., Maslen, J., Binns, D., Harte, N., Lopez, R., and Apweller, R. The gene ontology annotation (GOA) database: sharing knowledge in Uniprot with gene ontology. Nucleic Acids Res 32, D262, 2004.

15. Assou, S., Le Carrour, T., Tondeur, S., Ström, S., Gabelle, A., Marty, S., Nadal, L., Pantesco, V., Réme, T., Hugnot, J.P., Gasca, S., Hovatta, O., Hamamah, S., Klein, B., and De Vos, J. A meta-analysis of human embryonic stem cells transcriptome integrated into a web-based expression atlas. Stem Cells 25, 961, 2007.

16. Sturn, A., Quackenbush, J., and Trajanoski, Z. Genesis: cluster analysis of microarray data. Bioinformatics 18, 207, 2002.

17. Heins, N., Lindahl, A., Karlsson, U., Rehnström, M., Calsander, G., Emanuelsson, K., Hanson, C., Semb, H., Björquist, P., Sartipy, P., and Hyllner, J. Clonal derivation and characterization of human embryonic stem cell lines. J Biotechnol 122, 511, 2006.

18. Bhattacharya, B., Miura, T., Brandenberger, R., Mejido, J., Luo, Y., Yang, A.X., Joshi, B.H., Ginis, I., Thies, R.S., Amit, M., Lyons, I., Condie, B.G., Itskovitz-Eldor, J., Rao, M.S., and Purl, R.K. Gene expression in human embryonic stem cell lines: unique molecular signature. Blood 103, 2956, 2004.

19. Pan, G., and Thomson, J.A. Nanog and transcriptional networks in embryonic stem cell pluripotency. Cell Res 17, 42, 2007.

20. Adewumi, O., Aflatoonian, B., Ahrlund-Richter, L., Amit, M., Andrews, P.W., Beighton, G., Bello, P.A., Benvenisty, N., Berry, L.S., Bevan, S., Blum, B., Brooking, J., Chen, K.G., Choo, A.B., Churchill, G.A., Corbel, M., Damjanov, I., Draper, J.S., Dvorak, P., Emanuelsson, K., Fleck, R.A., Ford, A., Gertow, K., Gertsenstein, M., Gokhale, P.J., Hamilton, R.S., Hampl, A., Healy, L.E., Hovatta, O., Hyllner, J., Imreh, M.P., Itskovitz-Eldor, J., Jackson, J., Johnson, J.L., Jones, M., Kee, K., King, B.L., Knowles, B.B., Lako, M., Lebrin, F., Mallon, B.S., Manning, D., Mayshar, Y., McKay, R.D., Michalska, A.E., Mikkola, M., Milelkovsky, M., Minger, S.L., Moore, H.D., Mummery, C.L., Nagy, A., Nakatsujl, N., O'Brien, C.M., Oh, S.K., Olsson, C., Otonkoski, T., Park, K.Y., Passier, R., Patel, H., Patel, M., Pedersen, R., Pera, M.F., Piekarczyk, M.S., Pera, R.A., Reubinoff, B.E., Robins, A.J., Rossant, J., Rugg-Gunn, P., Schulz, T.C., Semb, H., Sherrer, E.S., Siemen, H., Stacey, G.N., Stojkovic, M., Suemori, H., Szatkiewicz, J., Turetsky, T., Tuuri, T., van den Brink, S., Vintersten, K., Vuoristo, S., Ward, D., Weaver, T.A., Young, L.A., and Zhang, W. Characterization of human embryonic stem cell lines by the International stem cell initiative. Nat Biotechnol 25, 803, 2007.

21. Hyslop, L., Stojkovic, M., Armstrong, L., Walter, T., Stojkovic, P., Przyborski, S., Herbert, M., Murdoch, A., Strachan, T., and Lako, M. Downregulation of NANOG induces differentiation of human embryonic stem cells to extraembryonic lineages. Stem Cells 23, 1035, 2005.

22. Rodda, D.J., Chew, J.L., Lim, L.H., Loh, Y.H., Wang, B., Ng, H.H., and Robson, P. Transcriptional regulation of nanog by OCT4 and SOX2. J Biol Chem 280, 24731, 2005.

23. Lim, L.S., Loh, Y.H., Zhang, W., Li, Y., Chen, X., Wang, Y., Bakre, M., Ng, H.H., and Stanton, L.W. Zic3 is required for maintenance of pluripotency in embryonic stem cells. Mol Biol Cell 18, 1348, 2007.

24. Yu, J., Vodyanik, M.A., Smuga-Otto, K., Antosiewicz-Bourget, J., Frane, J.L., Tian, S., Nie, J., Jonsdottir, G.A., Ruotti, V., Stewart, R., Slukvin, I.I., and Thomson, J.A. Induced pluripotent stem cell lines derived from human somatic cells. Science 318, 1917, 2007.

25. Babaie, Y., Herwig, R., Greber, B., Brink, T.C., Wruck, W., Groth, D., Lehrach, H., Burdon, T., and Adjaye, J. Analysis of Oct4-dependent transcriptional networks regulating selfrenewal and pluripotency in human embryonic stem cells. Stem Cells 25, 500, 2007.

26. Boyer, L.A., Lee, T.I., Cole, M.F., Johnstone, S.E., Levine, S.S., Zucker, J.P., Guenther, M.G., Kumar, R.M., Murray, H.L., Jenner, R.G., Gifford, D.K., Melton, D.A., Jaenisch, R., and Young, R.A. Core transcriptional regulatory circuitry in human embryonic stem cells. Cell 122, 947, 2005.

27. Maldonado-Saldivia, J., van den Bergen, J., Krouskos, M., Gilchrist, M., Lee, C., Li, R., Sinclair, A.H., Surani, M.A., and Western, P.S. Dppa2 and Dppa4 are closely linked SAP motif genes restricted to pluripotent cells and the germ line. Stem Cells 25, 19, 2007.

28. Inamdar, M.S., Venu, P., Srinivas, M.S., Rao, K., and VijayRaghavan, K. Derivation and characterization of two sibling human embryonic stem cell lines from discarded grade III embryos. Stem Cells Dev 18, 423, 2009.

29. Ciccodicola, A., Dono, R., Obici, S., Simeone, A., Zollo, M., and Persico, M.G. Molecular characterization of a gene of the EGF family expressed in undifferentiated human NTERA2 teratocarcinoma cells. EMBO J 8, 1987, 1989.

30. Strizzi, L., Bianco, C., Normanno, N., and Salomon, D. Cripto-1: a multifunctional modulator during embryogenesis and oncogenesis. Oncogene 24, 5731, 2005.

31. Pasquale, E.B. The Eph family of receptors. Curr Opin Cell Biol 9, 608, 1997.

32. Rhee, I., Bachman, K.E., Park, B.H., Jair, K.W., Yen, R.W., Schuebel, K.E., Cui, H., Feinberg, A.P., Lengauer, C., Kinzier, K.W., Baylin, S.B., and Vogelstein, B. DNMT1 and DNMT3b cooperate to silence genes in human cancer cells. Nature 416, 552, 2002.

33. Huang, Q., Raya, A., DeJesus, P., Chao, S.H., Quon, K.C., Caldwell, J.S., Chanda, S.K., Izpisua-Belmonte, J.C., and Schultz, P.G. Identification of p53 regulators by genomewide functional analysis. Proc Natl Acad Sci USA 101, 3456, 2004.

34. Yang, H., Filipovic, Z., Brown, D., Breit, S.N., and Vassilev, L.T. Macrophage inhibitory cytokine-1: a novel biomarker for p53 pathway activation. Mol Cancer Ther 2, 1023, 2003.

35. McPherson, L.A., Loktev, A.V., and Weigel, R.J. Tumor suppressor activity of AP2alpha mediated through a direct interaction with p53. J Biol Chem 277, 45028, 2002.

36. Li, J., Hassan, G.S., Williams, T.M., Minetti, C., Pestell, R.G., Tanowitz, H.B., Frank, P.G., Sotgia, F., and Lisanti, M.P. Loss of caveolin-1 causes the hyper-proliferation of intestinal crypt stem cells, with increased sensitivity to whole body gamma-radiation. Cell Cycle 4, 1817, 2005.

37. Rubio, D., Garcia, S., Paz, M.F., De la Cueva, T., LopezFernandez, L.A., Lloyd, A.C., Garcia-Castro, J., and Bernad, A. Molecular characterization of spontaneous mesenchymal stem cell transformation. PLoS ONE 3, e1398, 2008.

38. Raabe, E.H., Abdurrahman, L., Behbehani, G., and Arceci, R.J. An SNF2 factor involved in mammalian development and cellular proliferation. Dev Dyn 221, 92, 2001. 
39. Geiman, T.M., and Muegge, K. Lsh, an SNF2/helicase family member, is required for proliferation of mature $\mathrm{T}$ lymphocytes. Proc Natl Acad Sci USA 97, 4772, 2000.

40. Sun, L.Q., Lee, D.W., Zhang, Q., Xiao, W., Raabe, E.H., Meeker, A., Miao, D., Huso, D.L., and Arceci, R.J. Growth retardation and premature aging phenotypes in mice with disruption of the SNF2-like gene, PASG. Genes Dev 18, 1035, 2004.

41. Izumi, M., Yatagai, F., and Hanaoka, F. Cell cycle-dependent proteolysis and phosphorylation of human Mcm10. J Biol Chem 276, 48526, 2001.

42. Clase, K.L., Mitchell, P.J., Ward, P.J., Dorman, C.M., Johnson, S.E., and Hannon, K. FGF5 stimulates expansion of connective tissue fibroblasts and inhibits skeletal muscle development in the limb. Dev Dyn 219, 368, 2000.

43. Zhang, X., Neganova, I., Przyborski, S., Yang, C., Cooke, M., Atkinson, S.P., Anyfantis, G., Fenyk, S., Keith, W.N., Hoare, S.F., Hughes, O., Strachan, T., Stojkovic, M., Hinds, P.W., Armstrong, L., and Lako, M. A role for NANOG in G1 to $S$ transition in human embryonic stem cells through direct binding of CDK6 and CDC25A. J Cell Biol 184, 67, 2009.

44. Ryu, S., Holzschuh, J., Erhardt, S., Ettl, A.K., and Driever, W. Depletion of minichromosome maintenance protein 5 in the zebrafish retina causes cell-cycle defect and apoptosis. Proc Natl Acad Sci USA 102, 18467, 2005.

45. Komurasaki, T., Toyoda, H., Uchida, D., and Morimoto, S. Epiregulin binds to epidermal growth factor receptor and ErbB-4 and induces tyrosine phosphorylation of epidermal growth factor receptor, ErbB-2, ErbB-3 and ErbB-4. Oncogene 15, 2841, 1997.

46. Brown, J.R., Nigh, E., Lee, R.J., Ye, H., Thompson, M.A., Saudou, F., Pestell, R.G., and Greenberg, M.E. Fos family members induce cell cycle entry by activating cyclin D1. Mol Cell Biol 18, 5609, 1998.

47. Fujiki, K., Duerr, E.M., Kikuchi, H., Ng, A., Xavier, R.J., Mizukami, Y., Imamura, T., Kuike, M.H., and Chung, D.C. Hoxc6 is overexpressed in gastrointestinal carcinoids and interacts with JunD to regulate tumor growth. Gastroenterology 135, 907, 16 e1-2, 2008.

48. Kim, J., Kang, J.W., Park, J.H., Choi, Y., Choi, K.S., Park, K.D., Baek, D.H., Seong, S.K., Min, H.K., and Kim, H.S. Biological characterization of long-term cultured human mesenchymal stem cells. Arch Pharm Res 32, 117, 2009.

49. Henson, J.D., Neumann, A.A., Yeager, T.R., and Reddel, R.R. Alternative lengthening of telomeres in mammalian cells. Oncogene 21, 598, 2002.

50. Bharadwaj, R., and $\mathrm{Yu}, \mathrm{H}$. The spindle checkpoint, aneuploidy, and cancer. Oncogene 23, 2016, 2004.

51. Dobles, M., Liberal, V., Scott, M.L., Benezra, R., and Sorger, P.K. Chromosome missegregation and apoptosis in mice lacking the mitotic checkpoint protein Mad2. Cell 101, 635, 2000.

52. Langton, S., and Gudas, L.J. CYP26A1 knockout embryonic stem cells exhibit reduced differentiation and growth arrest in response to retinoic acid. Dev Biol 315, 331, 2008.

53. Yocum, A.K., Gratsch, T.E., Leff, N., Strahler, J.R., Hunter, C.L., Walker, A.K., Michallidis, G., Omenn, G.S., O'Shea, K.S., and Andrews, P.C. Coupled global and targeted proteomics of human embryonic stem cells during induced differentiation. Mol Cell Proteomics 7, 750, 2008.

54. Finnis, M.L., and Gibson, M.A. Microfibril-associated glycoprotein-1 (MAGP-1) binds to the pepsin-resistant domain of the alpha3 (VI) chain of type VI collagen. J Biol Chem 272, 22817, 1997.
55. Schuldiner, M., Yanuka, O., Itskovitz-Eldor, J., Melton, D.A., and Benvenisty, N. Effects of eight growth factors on the differentiation of cells derived from human embryonic stem cells. Proc Natl Acad Sci USA 97, 11307, 2000.

56. Komori, T. Runx2, a multifunctional transcription factor in skeletal development. J Cell Biochem 87, 1, 2002.

57. Fan, Z., Yamaza, T., Lee, J.S., Yu, J., Wang, S., Fan, G., Shi, S., and Wang, C.Y. BCOR regulates mesenchymal stem cell function by epigenetic mechanisms. Nat Cell Biol 11, 1002, 2009.

58. Sakuma, R., Ohnishi, Yi, Y., Meno, C., Fujii, H., Juan, H., Takeuchi, J., Ogura, T., Li, E., Miyazono, K., and Hamada, $H$. Inhibition of Nodal signalling by Lefty mediated through interaction with common receptors and efficient diffusion. Genes Cells 7, 401, 2002.

59. Conlon, F.L., Lyons, K.M., Takaesu, N., Barth, K.S., Kispert, A., Herrmann, B., and Robertson, E.J. A primary requirement for nodal in the formation and maintenance of the primitive streak in the mouse. Development 120, 1919, 1994.

60. Li, X., Chen, Y., Schéele, S., Arman, E., Haffner-Krausz, R., Ekblom, P., and Lonai, P. Fibroblast growth factor signaling and basement membrane assembly are connected during epithelial morphogenesis of the embryoid body. J Cell Biol 153, 811, 2001.

61. Hailesellasse Sene, K., Porter, C.J., Palidwor, G., PerezIratxeta, C., Muro, E.M., Campbell, P.A., Rudnicki, M.A., and Andrade-Navarro, M.A. Gene function in early mouse embryonic stem cell differentiation. BMC Genomics 8, 85, 2007.

62. Ivkovic, S., Yoon, B.S., Popoff, S.N., Safadi, F.F., Libuda, D.E., Stephenson, R.C., Daluiski, A., and Lyons, K.M. Connective tissue growth factor coordinates chondrogenesis and angiogenesis during skeletal development. Development 130, 2779, 2003.

63. Ferrell, C.M., Dorsam, S.T., Ohta, H., Humphries, R.K., Dervnck, M.K., Hagg, C., Largman, C., and Lawrence, H.J. Activation of stem-cell specific genes by HOXA9 and HOXA10 homeodomain proteins in CD34+ human cord blood cells. Stem Cells 23, 644, 2005.

64. Hobert, O., and Westphal, H. Functions of LIM-homeobox genes. Trends Genet 2, 75, 2000

65. Kawakami, Y., Uchiyama, Y., Rodriguez Esteban, C., Inenaga, T., Koyano-Nakagawa, N., Kawakami, H., Marti, M., Kmita, M., Monaghan-Nichols, P., Nishinakamura, R., and Izpisua Belmonte, J.C. Sall genes regulate region-specific morphogenesis in the mouse limb by modulating Hox activities. Development 4, 585, 2009.

66. Gang, E.J., Bosnakovski, D., Simsek, T., To, K., and Perlingeiro, R.C. Pax3 activation promotes the differentiation of mesenchymal stem cells toward the myogenic lineage. Exp Cell Res 8, 1721, 2008.

67. Merlo, G.R., Zerega, B., Paleari, L., Trombino, S., Mantero, S., and Levi, G. Multiple functions of Dlx genes. Int J Dev Biol 6, 619, 2000.

68. Satokata, I., Ma, L., Ohehima, H., Bei, M., Woo, I., Nishizawa, K., Maeda, T., Takano, Y., Uchiyama, M., Heaney, S., Peters, H., Tang, Z., Maxson, R., and Maas, R. Msx2 deficiency in mice causes pleiotropic defects in bone growth and ectodermal organ formation. Nat Genet 4, 391, 2000.

69. Vecchione, A., Croce, C.M., and Baldassarre, G. Fez1/Lzts1 a new mitotic regulator implicated in cancer development. Cell Div 2, 24, 2007.

70. Califano, D., Pignata, S., Pisano, C., Greggi, S., Laurelli, G., Losito, N.S., Ottaiano, A., Gallipoli, A., Pasquinelli, R., 
De, Simone, V., Cirombella, R., Fusco, A., and Chiappetta, G. FEZ1/LZTS1 protein expression in ovarian cancer. J Cell Physiol 2, 382, 2010.

71. Vecchione, A., Ishii, H., Baldassarre, G., Bassi, P., Trapasso, F., Alder, H., Pagano, F., Gomella, L.G., Croce, C.M., and Baffa, R. FEZ1/LZTS1 is down-regulated in high-grade bladder cancer, and its restoration suppresses tumorigenicity in transitional cell carcinoma cells. Cancer Epidemiol Biomarkers Prev 2, 194, 2006.

72. Romieu-Mourez, R., Francois, M., Boivin, M.N., Stagg, J., and Galipeau, J. Regulation of MHC class II expression and antigen processing in murine and human mesenchymal stromal cells by IFN-gamma, TGF-beta, and cell density. J Immunol 179, 1549, 2007.
Address correspondence to: Giuseppe Maria de Peppo, M.Sc.

Department of Biomaterials Sahlgrenska Academy at University of Gothenburg

Box 412, SE 40530

Göteborg

Sweden

E-mail: giuseppe.de.peppo@biomaterials.gu.se

Received: September 19, 2009

Accepted: February 4, 2010

Online Publication Date: March 10, 2010 